This item was submitted to Loughborough's Research Repository by the author.

Items in Figshare are protected by copyright, with all rights reserved, unless otherwise indicated.

\title{
An investigation into the effect of a post-electroplating electrochemical oxidation treatment on tin whisker formation
}

PLEASE CITE THE PUBLISHED VERSION

http://dx.doi.org/10.1007/s11664-014-3396-7

\section{PUBLISHER}

Springer / @ The Minerals, Metals \& Materials Society

\section{VERSION}

AM (Accepted Manuscript)

\section{PUBLISHER STATEMENT}

This work is made available according to the conditions of the Creative Commons Attribution-NonCommercialNoDerivatives 4.0 International (CC BY-NC-ND 4.0) licence. Full details of this licence are available at: https://creativecommons.org/licenses/by-nc-nd/4.0/

\section{LICENCE}

CC BY-NC-ND 4.0

\section{REPOSITORY RECORD}

Ashworth, Mark A., D. Haspel, L. Wu, G.D. Wilcox, and Roger J. Mortimer. 2015. "An Investigation into the Effect of a Post-electroplating Electrochemical Oxidation Treatment on Tin Whisker Formation". figshare. https://hdl.handle.net/2134/16990. 
An Investigation into the Effect of a Post-electroplating Electrochemical

Oxidation Treatment on Tin Whisker Formation

M.A. ASHWORTH ${ }^{1}$, D. HASPEL ${ }^{1}$, L. WU ${ }^{1}$, G.D. WILCOX ${ }^{1}$ and R.J. MORTIMER ${ }^{2}$

${ }^{1}$ Department of Materials, Loughborough University, Loughborough, Leicestershire, LE11 3TU

${ }^{2}$ Department of Chemistry, Loughborough University, Loughborough, Leicestershire, LE11 3TU

Corresponding author:

Email: m.a.ashworth@lboro.ac.uk,

Tel: $\quad+44(0) 1509225406$ 


\begin{abstract}
Since the 'cracked oxide theory' was proposed by Tu in 1994 [1], there has only been a limited number of studies that have sought to investigate the effect of the Sn oxide on whisker growth. The current study has used electrochemical oxidation to produce oxide films, which has enabled the effect of the surface oxide thickness on whisker growth to be established. The effect of oxide thickness on whisker growth has been investigated for tin electrodeposits on both $\mathrm{Cu}$ and brass substrates. The influence of applied oxidation potential on the thickness of the Sn oxide film has been investigated using x-ray photoelectron spectroscopy (XPS) for potassium bicarbonate-carbonate and borate buffer electrolyte solutions. Whisker growth from electrochemically oxidised $\mathrm{Sn}-\mathrm{Cu}$ deposits on $\mathrm{Cu}$ and $\mathrm{Sn}$ deposits on brass has been investigated and compared with samples left to develop a native air-formed oxide. XPS studies show that the thickness of the electrochemically formed Sn oxide film is dependent on the applied oxidation potential and the total charge passed. Subsequent whisker growth studies demonstrate that electrochemically oxidised Sn-Cu deposits on $\mathrm{Cu}$ and $\mathrm{Sn}$ deposits on brass are significantly less susceptible to whisker growth than those having a native oxide film. For Sn deposits on brass, the electrochemically formed Sn oxide greatly reduces $\mathrm{Zn}$ oxide formation at the surface of the tin deposit, which results in whisker mitigation. For $\mathrm{Sn}-\mathrm{Cu}$ deposits on $\mathrm{Cu}$, the reduction in whisker growth must simply derive from the increased thickness of the Sn oxide, i.e. the Sn oxide film has an important role in stemming the development of whiskers.
\end{abstract}

Keywords: Tin, electrochemical oxidation, electrodeposition, whisker growth, zinc, diffusion 


\section{Introduction}

The role of the surface oxide film in the growth of tin whiskers has not been widely reported in the literature. The cracked oxide theory put forward by Tu [1-3], proposed that the Sn oxide film played a critical role in the growth of tin whiskers by suppressing relaxation of the deposit via uniform creep of tin atoms to the surface of the deposit [4]. Stress relaxation in deposits resulting from removal of the oxide layer was later demonstrated experimentally [5,6]. Lee and Lee [7] also stated that for whisker growth to occur, it was necessary to break the oxide at certain weak points on the surface, from which whiskers grew to relieve stress. It was also suggested that very thick oxides would physically block the growth of whiskers or hillocks [2,3]. In the absence of an oxide film, no whisker growth was considered likely; this assumption was based on a study by Chang and Vook [8], which showed that, in the absence of a surface oxide, no hillock formation under compressive stress occurred on vapour deposited aluminium films. However, whisker formation was later reported for $\mathrm{Sn}-\mathrm{Cu}$ electrodeposits [9] that had been stored for 9 days under vacuum, after initially removing the surface oxide by ion beam sputtering. Subsequent real time focussed ion beam SEM (FIBSEM) studies by Jadhav et al. [10], however, indicated that removal of the oxide could relieve stress and hence reduce the driving force for whisker and hillock formation. Further evidence to suggest that the surface oxide plays an important role in whisker growth can be inferred from the observation of 'growth striations' on tin whiskers [11]. These were associated with discontinuous whisker growth as a result of repeated fracture and self-healing of the air-formed Sn oxide at the whisker base.

Further insight into the possible influence of the surface oxide on whisker formation may be obtained from a comparison of whisker growth rates during thermal cycling in air and vacuum environments. Suganuma et al. [12] showed that whisker growth was reduced for tin electrodeposits thermally cycled in air, compared with those tested under vacuum, which may indicate that whisker growth was more difficult on the samples thermally cycled in air due to the increased thickness of the Sn oxide layer. 
Given the potential influence of the surface oxide on whisker growth, and the relative scarcity of research related to this phenomenon, the current study was undertaken to investigate the effect of electrochemical oxidation on whisker growth. Electrochemical oxidation is an ideal method for the development of Sn oxides since other characteristic features of the tin deposit should be unaffected by the oxidation process; whereas the formation of Sn oxides at elevated temperatures is likely to be accompanied by other changes to the tin deposit (e.g. residual stress levels [7] and intermetallic type and distribution [13]). Electrochemical oxidation has been performed in two different electrolyte solutions; a borate buffer solution $[14,15]$ and a potassium bicarbonate-carbonate solution [16]. Initial cyclic voltammetry trials were performed in both electrolyte solutions to study the tin oxidation processes, followed by oxidation at selected potentials identified from the cyclic voltammagrams. The thickness of the resultant Sn oxide films was determined by XPS depth profiling. The effect of the electrochemically formed oxide on whisker growth was established for both Sn deposits on brass and $\mathrm{Sn}-\mathrm{Cu}$ deposits on $\mathrm{Cu}$.

\section{Experimental}

\section{Deposition of Tin}

Pure Sn and Sn-Cu alloys were electrodeposited onto brass (63 \% Cu / 37 \% Zn, 0.38 mm thickness) and $\mathrm{Cu}$ (99.9 \%, 0.1 mm thickness) substrates, respectively, using a bright acid Sn electroplating solution, which is comprised of $60 \mathrm{~g} \mathrm{~L}^{-1}$ tin sulphate, $70 \mathrm{ml} \mathrm{L}^{-1}$ sulphuric acid and $40 \mathrm{ml} \mathrm{L}^{-1}$ Tinmac Stannolyte, a proprietary additive (MacDermid). Electrodeposition of $2 \mu \mathrm{m}$ pure $\mathrm{Sn}$ onto $\mathrm{Cu}$ and brass was carried out using a current density of $20 \mathrm{~mA} \mathrm{~cm}{ }^{-2}$ (corresponding to a deposition rate of $\sim 1 \mu \mathrm{m} \min ^{-1}$ ). The $\mathrm{Sn}-\mathrm{Cu}$ bath was prepared with a $\mathrm{Cu}^{2+}$ concentration of $10 \mathrm{mmol} \mathrm{L}^{-1}$ by the addition of $\mathrm{CuSO}_{4}$ to the pure $\mathrm{Sn}$ bath. For Sn-Cu electrodeposited onto $\mathrm{Cu}$ at $10 \mathrm{~mA} \mathrm{~cm}{ }^{-2}$ this resulted in a uniform deposit with a $\mathrm{Cu}$ content of $\sim 1$ wt $\%$.

Test coupons with dimensions $2 \times 4 \mathrm{~cm}$ were used with an electroplated area of $2 \times 2 \mathrm{~cm}$. The coupons were used in the as-supplied condition with no additional polishing or grinding operations. Electrodeposition of pure Sn was carried out using a $99.95 \%$ Sn foil anode $(0.25$ 
$\mathrm{mm}$ ) whilst the $\mathrm{Sn}-\mathrm{Cu}$ alloy was deposited using a platinised titanium anode. Immediately prior to deposition, all the substrates were degreased using acetone, pickled for $60 \mathrm{~s}$ in a $20 \%$ v/v solution of sulphuric acid (SG 1.83), rinsed in deionised water and dried using hot air. The thicknesses of the pure Sn and Sn-Cu deposits were $10 \mu \mathrm{m}$ for cyclic voltammetry and electrochemical oxidation trials and $1 \mu \mathrm{m}$ or $2 \mu \mathrm{m}$ for whisker growth studies, the latter thin coatings being utilised to promote whisker growth.

\section{Preparation of Electrolyte Solutions for Tin Oxidation}

Two electrolyte solutions were selected for electrochemical oxidation of the Sn deposits; a pH 8.4 borate buffer (9.55 $\mathrm{g} \mathrm{L}^{-1}$ sodium borate and $6.18 \mathrm{~g} \mathrm{~L}^{-1}$ boric acid, both Sigma-Aldrich) and a $\mathrm{pH} 8.9$ potassium bicarbonate/potassium carbonate $\left(75.09 \mathrm{~g} \mathrm{~L}^{-1}\right.$ of potassium bicarbonate and $6.91 \mathrm{~g} \mathrm{~L}^{-1}$ of potassium carbonate, both Sigma-Aldrich). Both electrolyte solutions were prepared using deionised water and the $\mathrm{pH}$ was adjusted to the required level using additions of sodium hydroxide.

\section{Cyclic Voltammetry}

Cyclic voltammetry was carried out for Sn electroplated deposits in naturally aerated $\mathrm{pH} 8.4$ borate buffer and $\mathrm{pH} 8.9$ potassium bicarbonate/potassium carbonate electrolyte solutions to determine the location of the oxidation peaks. Analyses were conducted using an EG\&G Princeton Applied Research model 263A potentiostat by means of a 3-electrode cell comprising of a static Sn electrodeposit as the working electrode, a saturated calomel reference electrode (SCE) and a platinised titanium counter electrode. The electrode potential was swept from $-1.1 \mathrm{~V}$ up to $1.2 \mathrm{~V}$, reversed to $-1.5 \mathrm{~V}$ and then returned to $-1.1 \mathrm{~V}$ (all vs. SCE) using a linear scan rate of $10 \mathrm{mV} \mathrm{s}^{-1}$. Multiple cycles were performed for each test and the second scan selected for analysis to reduce the influence of the pre-existing air-formed oxide on the results.

\section{Electrochemical Oxidation of Tin}

Electrochemical oxidation was performed immediately after Sn deposition using an EG\&G Princeton Applied Research model 263A potentiostat and the 3-electrode cell described 
previously. After immersion into the naturally aerated electrolyte solution, the tin deposit was initially held at a potential of $-1.5 \mathrm{~V}$ vs. SCE to reduce the pre-existing oxide. When hydrogen evolution was observed the potential was increased to the selected value for oxidation. The effect of oxidation potential on the thickness of the Sn oxide was investigated for both borate buffer and potassium bicarbonate-carbonate electrolyte solutions.

\section{Characterisation of Electrochemical Oxides}

The composition and thickness of the oxide films produced by electrochemical oxidation was determined by x-ray photoelectron spectroscopy (XPS) using a Thermo-Scientific K-Alpha xray photoelectron spectrometer. Sputter depth profiling was performed using $200 \mathrm{eV}$ argon ions with an estimated etch rate of $\sim 0.6 \mathrm{~nm} \mathrm{~min}^{-1}$. XPS analysis was, unless otherwise stated, carried out 1 day after tin deposition and electrochemical oxidation.

\section{Whisker Growth Studies}

The effect of the electrochemical oxides on whisker growth was assessed using $2 \mu \mathrm{m}$ tin deposits on brass and $1 \mu \mathrm{m}$ and $2 \mu \mathrm{m}$ Sn-Cu alloy deposits on $\mathrm{Cu}$ substrates. Typically, three samples were prepared for each electrochemical oxidation treatment. After deposition and electrochemical oxidation the samples were stored at room temperature $\left(\sim 20^{\circ} \mathrm{C}\right)$. Whisker growth was evaluated using optical microscopy and scanning electron microscopy (SEM). Whisker densities were measured using an optical microscope with an objective magnification of x20. The analysed area was $\sim 1 \mathrm{~cm}^{2}$ for samples electrochemically oxidised at $1.2 \mathrm{~V}$ vs. SCE and $0.26 \mathrm{~cm}^{2}$ for samples electrochemically oxidised at $-0.66 \mathrm{~V}$ vs. SCE. SEM analysis of the tin deposits was undertaken using a Carl Zeiss Leo 1530 VP field emission gun SEM (FEGSEM) equipped with an Oxford Instruments X-Max $80 \mathrm{~mm}^{2}$ detector for energy dispersive x-ray spectroscopy (EDS). Details of the samples prepared for whisker growth studies are given in Table I.

\section{Results and discussion}

\section{Electrochemical Oxidation and Characterisation}


Cyclic voltammograms for the oxidation and reduction of electrodeposited $\mathrm{Sn}$ in borate buffer and potassium bicarbonate-carbonate solutions are shown in Figure 1 (a) and (b). The cathodic current densities at the start of the potential sweeps were $\sim 2 \times 10^{-5} \mathrm{~A} \mathrm{~cm}^{-2}$ and $1 \times 10^{-4} \mathrm{~A} \mathrm{~cm}^{-2}$ for the borate buffer and potassium bicarbonate-carbonate electrolyte solutions, respectively. Two main oxidation peaks are evident in both electrolyte solutions. For the borate buffer electrolyte solution (Figure 1 (a)) oxidation peaks are evident at $-0.82 \mathrm{~V}$ (peak I) and -0.64 V vs. SCE, (peak II), less clearly defined broad peaks are also observed at approximately $0 \mathrm{~V}$ (peak III) and $0.7 \mathrm{~V}$ vs. SCE (peak IV). The increase in current density observed at $\sim 1.1 \mathrm{~V}$ vs. SCE is due to oxygen evolution (peak V). Two distinct reduction peaks are observed on the reverse sweep (labelled peaks VI and VII), together with other less clearly defined reduction peaks. For the potassium bicarbonate-carbonate electrolyte solution (Figure 1 (b)) oxidation peaks are evident at -0.83V (peak I) and -0.66 V vs. SCE (peak II), along with an increase in current density at $~ 1.1 \mathrm{~V}$ vs. SCE due to oxygen evolution (peak III). Distinct reduction peaks are evident at approximately $-0.6 \mathrm{~V},-1.1 \mathrm{~V}$ and $-1.4 \mathrm{~V}$ vs. SCE, peaks IV, V, and VI, respectively.

Peak (I) has been associated previously with the active dissolution of Sn to Sn(II) whilst peak (II) has been attributed to the to the formation of Sn (IV) [15-17]. The broad, slowly decreasing slope, on peak (II) observed for the potassium bicarbonate-carbonate electrolyte solution was considered by Drogowska et al. [17] to correspond to a dehydration reaction that resulted, via multiple reaction steps, in the formation of $\mathrm{SnO}_{2}$. In a later study of Sn oxides formed in pH 7.5 borate buffer, Diaz et al. [14] proposed that peaks (I) and (II) both corresponded to the formation of Sn (II) species.

On the basis of the cyclic voltammetry results, electrochemical oxidation of freshly prepared Sn deposits was performed in the potassium bicarbonate- carbonate solution at the following potentials; $-0.83 \mathrm{~V}$ (peak (I)), $-0.66 \mathrm{~V}$ (peak (II)), $-0.5 \mathrm{~V}, 0.35 \mathrm{~V}$ and $1.2 \mathrm{~V}$ vs. SCE. The recorded current-time curves for oxidation at each of the potentials are shown in Figure 2; in each case the pre-existing oxide was firstly reduced by polarisation at $-1.5 \mathrm{~V}$ until hydrogen evolution was observed, at which point the potential was increased to the appropriate value. 
For each oxidation potential the total charge passed was $\sim 30 \mathrm{mC} \mathrm{cm}^{-2}$. All the current-time curves were characterised by an initial rapid reduction in current density followed by a gradual reduction in current density throughout the duration of the experiment. The highest current densities were obtained for samples oxidised at potentials corresponding to peaks (I) and (II) in Figure 1.

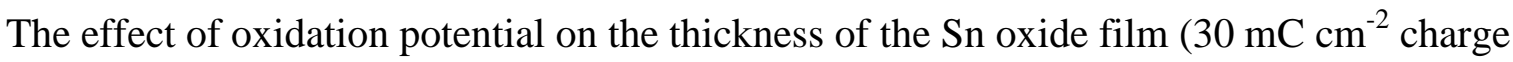
passed) is demonstrated by the high resolution XPS scans of the Sn 3d peak in Figure 3; analysis of a native air-formed oxide, prepared at the same time, is also included for

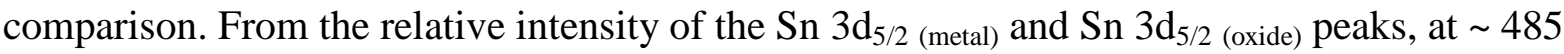
$\mathrm{eV}$ and $\sim 487 \mathrm{eV}$ respectively, it can be established that the thickness of the oxide film increases as the oxidation potential is increased from $-0.83 \mathrm{~V}$ to $1.2 \mathrm{~V}$ vs. SCE. The proportion of $\mathrm{Sn}$ (oxide) and $S n_{\text {(metal) }}$ species as a function of oxidation potential is shown in Table II, which also gives the binding energy of the metal and oxide peaks derived from curve fitting. From Table II it is evident that the intensity of the oxide peak from the sample oxidised at $-0.83 \mathrm{~V}$ vs. SCE is comparable to that of the native air-formed oxide, which suggests that most, if not all, the charge passed results in Sn dissolution rather than the formation of a stable Sn oxide. Increasing the potential to $-0.66 \mathrm{~V}$ and $-0.5 \mathrm{~V}$ vs. SCE results in a slightly increased oxide film thickness; only at the higher potentials investigated was the thickness of the oxide film increased notably. However, further trials demonstrated that considerably thicker oxides could be achieved at $-0.66 \mathrm{~V}$ vs. SCE by increasing the total charge passed. The oxygen depth profiles in Figure 4 show that oxidation at - $0.66 \mathrm{~V}$ vs. SCE for 5 min (equivalent to $\sim 100 \mathrm{mC} \mathrm{cm}^{-2}$ charge passed) resulted in an oxide thickness comparable to that of a sample oxidised at $1.2 \mathrm{~V}$ vs. SCE and that further increases in oxide thickness were achieved if the charge passed was increased. However, oxidation at $-0.66 \mathrm{~V}$ vs. SCE was found to result in partial dissolution of the tin deposit. As shown in Figure 4, the extent of the dissolution increased with increasing charge passed. The partial dissolution observed on the surface of the Sn deposits was most likely associated with individual Sn 
grains and their specific growth orientation given that the scale of the features is comparable to the Sn grain size that results from electrodeposition at $10 \mathrm{~mA} \mathrm{~cm}^{-2}$ [18].

The $\mathrm{Sn} 3 \mathrm{~d}_{5 / 2}$ peaks shown in Figure 3 could not be resolved into more than 2 peaks suggesting that only a single Sn oxide species is present. In addition, Table II shows that there was no significant variation in the binding energy of the $S n 3 d_{5 / 2}$ peak as a function of oxidation potential, i.e. the same oxide species is present in each case.

Additional electrochemical oxidation trials were undertaken at higher potentials in a borate buffer solution to determine whether thicker oxide films could be obtained, without partial dissolution of the Sn deposit. The gradual reduction in the intensity of the metal peak observed as the potential is increased from $1.2 \mathrm{~V}$ to $1.6 \mathrm{~V}$ and $2.0 \mathrm{~V}$ vs. SCE (Figure 5) indicates that slightly thicker oxide films are obtained at higher oxidation potentials. The measured binding energies of the $\mathrm{Sn} 3 \mathrm{~d}_{5 / 2}$ oxide peaks were; 487.3, 487.4 and $487.4 \mathrm{eV}$ after oxidation at $1.2 \mathrm{~V}, 1.6 \mathrm{~V}$ and $2.0 \mathrm{~V}$ vs. SCE, respectively, suggesting that the oxide species formed is the same at each potential and similar to those developed in the potassium bicarbonate-carbonate electrolyte solution (Table II).

The effect of electrochemical oxidation on whisker growth was investigated using $2 \mu \mathrm{m}$ Sn$\mathrm{Cu}$ deposits on $\mathrm{Cu}$ oxidised at 1.2 V vs. SCE in both borate buffer and potassium bicarbonate-carbonate electrolyte solutions. $2 \mu \mathrm{m}$ Sn deposits on brass were also oxidised at $1.2 \mathrm{~V}, 1.6 \mathrm{~V}$ and $2.0 \mathrm{~V}$ vs. SCE in borate buffer. In each case samples were prepared and left to develop a native air-formed oxide for comparison.

Sn Deposits on Brass: The Effect of Electrochemical Oxidation on Tin Whisker Formation

XPS depth profiles through the surface oxides of Sn deposits on brass, 1 day after Sn deposition and electrochemical oxidation at $1.2 \mathrm{~V}$ vs. SCE in borate buffer and potassium bicarbonate-carbonate electrolyte solutions, are shown in Figures 6 (a) and (b). A depth profile through a native air-formed oxide after 1 day is shown in Figure 6 (c). Examination of $\mathrm{Sn}$ (oxide) depth profiles indicates that, compared with the native oxide, the electrochemical Sn 
oxides are considerably thicker, which is consistent with the high resolution scans in Figure 3. The key feature of the depth profiles in Figures 6 is the sub-surface enrichment of Zn; the position of the peak $\mathrm{Zn}$ concentration suggests that the $\mathrm{Zn}$ is located at the interface between the Sn oxide and the underlying Zn metal. Importantly, given the crucial role $\mathrm{Zn}$ diffusion plays in whisker formation for Sn deposits on brass, the peak Zn concentration was both reduced and located further from the surface of the deposit for the electrochemically oxidised samples (Figures 6 (a) and (b)) compared to the native air-formed oxide (Figure 6 (c)); the approximate sputter times at which the highest Zn contents (given in brackets) were measured were $210 \mathrm{~s}$ ( 18 at \% Zn), $170 \mathrm{~s}(\sim 17$ at \% Zn) and $45 \mathrm{~s}$ ( 26 at \% Zn) for the potassium bicarbonate-carbonate, borate buffer and native oxides, respectively. No copper signal was detected during depth profiling, which indicates that the $\mathrm{Zn}$ was present in the tin deposit as a result of diffusion rather than being detected from the underlying brass substrate.

The effect of storage time on the thickness and composition of the native oxide formed on $2 \mu \mathrm{m}$ Sn deposits on brass is demonstrated by the electrochemical reduction curves in Figure 7. The plateau at $\sim-0.86 \mathrm{~V}$ vs. SCE corresponds to the reduction of Sn oxide [19] whilst that at $-1.2 \mathrm{~V}$ vs. SCE was demonstrated experimentally, by electrochemical reduction analysis of the air formed native oxide on a Zn foil sample, to relate to the reduction of Zn oxide. The width of the plateaux (corresponding to the charge passed) is proportional to the thickness of the oxide film. Between 7 and 28 days the thickness of the both the Sn oxide and Zn oxide layers increase with increasing storage time. However, the increase in the thickness of the $\mathrm{Zn}$ oxide layer, in particular between 21 and 28 days, is more pronounced, i.e. Zn oxide is formed preferentially.

XPS depth profiles measured for samples with a native oxide and an oxide formed electrochemically in borate buffer, after storage for $~ 300$ days at room temperature, are shown in Figure 8. Comparing Figure 8 (b) and Figure 6 (b), the elemental distribution at the surface of the Sn deposit having the electrochemically grown oxide (formed at $1.2 \mathrm{~V}$ vs. SCE in borate buffer) is not changed significantly. By comparison, the surface composition at the surface of the deposit left to develop a native air-formed oxide is considerably changed; the 
thickness of the Sn oxide film is only slightly increased but the measured Zn content at the interface between the Sn oxide and Sn metal has increased dramatically, from 26 to 45 at \%. The Zn (and oxygen) enrichment also extends much further into the Sn deposit. It is not easily established whether Zn is present in the metallic or oxidised state using XPS since there is no discernible shift in binding energy [20]. However, the presence of the Zn Auger peak at a binding energy of $\sim 499 \mathrm{eV}$ in Figure 3 (a) - (e) shows that, in the case of Sn deposits with thin oxide films, either air-formed or electrochemically grown at low potentials, the $\mathrm{Zn}$ on the un-sputtered surface is present, at least in part, in the oxidised state [20]. For electrochemically oxidised surfaces with thicker oxide films (e.g. 1.2 V vs. SCE in borate buffer, Figure 3 (f)), no Zn Auger peak is observed in the high resolution scans obtained prior to sputtering. However, for surfaces sputtered to the location at which the highest Zn content is measured, a Zn Auger peak corresponding to the oxidised state is clearly evident (Figure 9). At this position, the total measured oxygen content is $\sim 24$ at \% whilst the $\mathrm{Sn}$ (oxide) content is $\sim 14$ at \% and the $\mathrm{Zn}$ content is $\sim 25$ at \%; given the presence of $\mathrm{ZnO}$, this suggests that $\mathrm{Sn}$ at this location is present as SnO. High resolution XPS scans indicate a gradual slight reduction in the measured binding energy of the $\mathrm{Sn}_{\text {(oxide) }}$ peak from $487.0 \mathrm{eV}$ at the outer surface to $486.7 \mathrm{eV}$ at the location of the maximum $\mathrm{Zn}$ content.

The secondary electron images in Figure 10 show a clear difference in surface appearance between samples with native air-formed oxides and those with oxides electrochemically formed in borate buffer (after 270 days storage at room temperature). The surface of the native air-formed oxide shows distinctive dark contrast regions at the grain boundaries of the Sn grains; as shown in Figure 11, such features correspond to regions with high Zn and O contents. No such regions were evident on samples with electrochemically formed oxides. Optical microscope and SEM analyses of these samples after 270 days storage at room temperature showed a dramatic difference in whisker growth. No whiskers were observed on any of the Sn deposits on brass with electrochemically formed oxides. In comparison, long filament whiskers were observed on each of the samples left to develop air-formed oxides (Figure 12). These results show that an electrochemically formed oxide, formed soon after 
deposition, is able to mitigate the formation of whiskers for Sn deposits on brass, by preventing the time-dependent formation of $\mathrm{ZnO}$ at the surface of the deposit, in particular at the Sn grain boundaries. This is accomplished by the electrochemically formed Sn oxide functioning as a barrier to the outward diffusion of $\mathrm{Zn}$ from the brass to the surface of the deposit. This explanation is supported by SEM/EDS analysis of regions of the Sn deposit surface that were Ar ion sputtered during acquisition of XPS depth profiles 300 days after Sn deposition and electrochemical oxidation. The EDS maps in Figure 13, recorded $~ 90$ days after sputtering (i.e. 390 days after Sn deposition), show that outside of the sputtered area (region 1) there is no Zn enrichment or little evidence of whisker growth evident on the deposit surface. In comparison, within the sputtered area (region 2) $\mathrm{Zn}$ (and O) enrichment is apparent at the deposit surface, which has resulted in the growth of a significant number of whiskers (Figure 13 (f)).

\section{Sn-Cu Deposits on Cu: The Effect of Electrochemical Oxidation on Tin Whisker Formation}

To more fully explore the ability of electrochemical oxides to mitigate whisker formation, 2 $\mu \mathrm{m}$ Sn-Cu deposits (containing 1 at $\% \mathrm{Cu}$ ) on $\mathrm{Cu}$ were investigated; the addition of $\mathrm{Cu}$ to Sn has been shown to promote rapid whisker growth compared with pure Sn [21], which allows results to be obtained within a reasonably short time-frame. An important consideration was to establish whether $\mathrm{Cu}$ was incorporated into the electrochemically formed oxide film, which would potentially have complicated interpretation of the results. However, XPS of a sample electrochemically oxidised in a potassium bicarbonate-carbonate electrolyte solution, indicated that $\mathrm{Cu}$ was not incorporated within the oxide film (Figure 14).

XPS depth profiles for oxygen measured 21 days after Sn-Cu deposition for a native airformed oxide and electrochemically formed oxides grown in borate buffer and potassium bicarbonate-carbonate solutions (1.2 V vs. SCE, $40 \mathrm{mC} \mathrm{cm}^{-2}$ charge passed) are shown in Figure 15. Results indicate that at a given potential and with equivalent charge passed the resultant oxide thickness is similar for oxidation in either borate buffer or potassium bicarbonate-carbonate electrolyte solutions. Furthermore, the binding energy of the Sn $3 d_{5 / 2}$ 
(oxide) peak was $\sim 487.2 \mathrm{eV}$ in each case, i.e. identical to that formed on pure $\mathrm{Sn}$ deposits on brass. Figure 15 also shows that increasing the amount of charge passed to $160 \mathrm{mC} \mathrm{cm}^{-2}$ in the potassium bicarbonate-carbonate electrolyte solution did not result in an increased thickness of oxide, which suggests that, at this potential, the thickness of the oxide is selflimiting. However, as demonstrated, thicker oxides may be achieved by electrochemical oxidation at other potentials (e.g. $1.6 \mathrm{~V}$ or $-0.66 \mathrm{~V}$ vs. SCE).

Optical and SEM analysis of the Sn-Cu deposits showed that long filament whiskers were not only present on samples left to develop air-formed oxides but also on those that were electrochemically oxidised after deposition; examples of whiskers observed in the SEM, 48 days after Sn-Cu deposition, are shown in Figure 16. Whilst electrochemical oxidation was not able to prevent the growth of long filament whiskers the number of whiskers observed was significantly reduced on the electrochemically oxidised samples compared with those with native oxides. A comparison of whisker densities, measured after 60 days and 180 days storage at room temperature is given in Figure 17. After 60 days, the average whisker density on the samples left to develop a native air-formed oxide was $221 \pm 14 \mathrm{~cm}^{-2}$. In comparison, average whisker densities on the samples electrochemically oxidised in borate buffer and potassium bicarbonate-carbonate electrolyte solutions were $22 \pm 5 \mathrm{~cm}^{-2}$ and $27 \pm 5 \mathrm{~cm}^{-2}$, respectively. 180 days after deposition, average whisker density on the samples left to develop a native air-formed oxide had increased to $1432 \pm 26 \mathrm{~cm}^{-2}$ whilst whisker densities on the electrochemically oxidised samples had increased to $128 \pm 33 \mathrm{~cm}^{-2}$ for the borate buffer electrolyte solution and $198 \pm 42 \mathrm{~cm}^{-2}$ for the potassium bicarbonate-carbonate electrolyte solution (Figure 17). It is worth noting that, after 180 days, whisker densities were consistently lower on samples electrochemically oxidised in borate buffer compared with those oxidised in the potassium bicarbonate-carbonate. SEM images comparing typical whisker densities and whisker lengths on Sn deposits left to develop native air-formed oxide films with those oxidised in borate buffer are shown in Figure 18.

To further investigate the effect of electrochemical oxidation on whisker growth, a $6 \mathrm{~cm} \times 2$ $\mathrm{cm} \mathrm{Cu}$ foil substrate was electrodeposited with $1 \mu \mathrm{m}$ of $\mathrm{Sn}-\mathrm{Cu}$ at $10 \mathrm{~mA} \mathrm{~cm}{ }^{-2}$. Regions of the 
sample were subsequently electrochemically oxidised in potassium bicarbonate-carbonate at a potential of $-0.66 \mathrm{~V}$ vs. SCE for 5, 20 and $30 \mathrm{~min}$, respectively. Part of the Sn-Cu deposit was also left to develop a native air-formed oxide, as shown in Figure 19. Measurement of whisker densities in the different regions was carried out using optical microscopy after storage at room temperature for $\sim 60$ days, the results of which are shown in Figure 20. Analyses show that 5 min oxidation at $-0.66 \mathrm{~V}$ vs. SCE, which results in an oxide thickness comparable to that produced by electrochemical oxidation at $1.2 \mathrm{~V}$ vs. SCE (Figure 4), results in a considerable reduction in whisker density compared with the sample left to develop a native air-formed oxide. Furthermore, further reductions in whisker density were evident with increasing oxidation time. For regions of the sample electrochemically oxidised for 20 and 30 min, whisker growth was often observed to be associated with areas of the $\mathrm{Sn}-\mathrm{Cu}$ electrodeposit that appeared less oxidised than the surrounding regions; illustrated in Figure 21. From Figure 21, it is also evident that considerable dissolution of Sn has occurred during electrochemical oxidation at -0.66 V vs. SCE. This is shown more clearly in Figure 22. Comparison with regions of the surface left to develop a native air-formed oxide (Figure 22 (a)) indicates that the extent of the dissolution increases with increasing oxidation time and that the distribution of the preferential dissolution is related to the grain structure of the Sn electrodeposit.

These results indicate that the characteristics of the Sn oxide surface can have a profound effect on whisker growth during storage at room temperature.

\section{Discussion}

\section{Effect of Electrolyte Solution and Oxidation Potential on Sn Oxide Formation}

XPS analysis of Sn deposits oxidised in both borate buffer and potassium bicarbonatecarbonate electrolyte solutions showed that, for a given charge passed, thickness of oxide achieved is a function of the applied oxidation potential, i.e. at higher oxidation potentials a thicker Sn oxide film is formed. Oxidation at the peak potentials, identified by cyclic voltammetry (Figure 1), resulted in oxide films that were comparable in thickness to those 
present on samples left to develop a native air-formed oxide. From this it may be inferred that, at least initially, oxidation at $-0.83 \mathrm{~V}$ and $-0.66 \mathrm{~V}$ vs. SCE does not result in the formation of a stable passive film; Shah and Davies reported that at low potentials, for anodic polarisation in $0.1 \mathrm{M}$ sodium borate solution, half the current contributed towards stannous oxide ( $\mathrm{SnO}$ ) formation whilst the remainder resulted in Sn dissolution as stannite ions $\left(\mathrm{Sn}(\mathrm{OH})_{3}{ }^{-}{ }^{2}{ }^{2} 22\right]$. Above $0.2 \mathrm{~V}$ vs. Ag/AgCl no Sn dissolution was observed and stannic oxide $\left(\mathrm{SnO}_{2}\right)$ formation at the oxide/solution interface was inferred [22]. Oxidation at $-0.66 \mathrm{~V}$ for longer times was shown to result in significant thickening of the oxide film; however, this was accompanied by dissolution of the Sn deposit, the extent of which increased with increasing oxidation time (Figure 4).

The thickness of Sn oxide films formed at $1.2 \mathrm{~V}$ vs. SCE in borate buffer and potassium bicarbonate-carbonate solutions is comparable whilst attempts to develop thicker oxide films by increasing the charge passed (at $1.2 \mathrm{~V}$ vs. SCE) were unsuccessful. On the basis of the XPS results it cannot be established conclusively whether $\mathrm{SnO}$ or $\mathrm{SnO}_{2}$ is formed during electrochemical oxidation due to the overlapping ranges of binding energy reported for $\mathrm{Sn}^{2+}$ and $\mathrm{Sn}^{4+}$ [23] or indeed whether a systematic change in the chemistry of the Sn oxide is evident as a function of applied oxidation potential; although Table II does indicate a slight increase in binding energy of the $S n 3 d_{5 / 2}$ (oxide) peak as the oxidation potential is increased. In general, the binding energies measured in this study for the $\mathrm{Sn} 3 \mathrm{~d}_{5 / 2}$ (oxide) peak (486.7 to $487.4 \mathrm{eV}$ ) lie within the range of values more typically associated with $\mathrm{SnO}_{2}[23,24]$. The measured binding energy of the $\mathrm{Sn} 3 \mathrm{~d}_{5 / 2}$ (oxide) peak was comparable for $\mathrm{Sn}-\mathrm{Cu}$ deposits on $\mathrm{Cu}$ and Sn deposits on brass.

\section{Effect of the Electrochemical Oxide on Tin Whisker Growth}

For Sn deposits on brass, the presence of the electrochemical oxide has a profound effect on whisker growth; to date only limited whisker growth has been observed on deposits electrochemically oxidised in a pH 8.4 borate buffer at $1.2 \mathrm{~V}, 1.6 \mathrm{~V}$ and $2.0 \mathrm{~V}$ vs. SCE. For Sn deposits on brass, the main driving force for whisker growth is the diffusion of $\mathrm{Zn}$ to the 
surface of the Sn deposit $[18,25,26]$. As shown in Figure 3 and 6, $\mathrm{Zn}$ is evident on the surface of $2 \mu \mathrm{m}$ Sn deposits on brass left to develop a native oxide, as a result of diffusion from the underlying brass substrate, within one day of deposition. In comparison, little Zn is detected on Sn deposits electrochemically oxidised at potentials of $1.2 \mathrm{~V}$ vs. SCE and higher. Importantly, the measured surface Zn concentration does not increase with time after electrodeposition for electrochemically oxidised samples, thereby avoiding the formation of extended areas of Zn oxide at the Sn grain boundaries on the deposit surface observed in the current work (Figures 10 and 11 and [18]) and a previous study [27]. Thus, Zn oxide formation is greatly reduced and whisker growth is suppressed, unless the electrochemically formed oxide is subsequently removed (e.g. by Ar ion sputtering).

For electrochemically oxidised $\mathrm{Sn}$-Cu deposits on $\mathrm{Cu}$, improved whisker resistance is derived by a different mechanism than for Sn on brass. In the case of Sn-Cu deposits, accelerated whisker growth results from the formation of $\mathrm{Cu}_{6} \mathrm{Sn}_{5}$ intermetallic, both at the interface with the Cu substrate [28] and throughout the thickness of the deposit [28,29]. It is unlikely that the rate of intermetallic formation would be influenced by the electrochemical oxidation of the Sn. Therefore, any reduction in whisker growth rates observed on electrochemically oxidised Sn deposits must, on the basis of Tu's cracked oxide theory [1], simply derive from an increase in the ability of the Sn oxide to resist the formation of localised cracks within the surface oxide. In Tu’s model, whisker growth occurs where cracks are formed at localised sites in the surface oxide due to the build-up of compressive stresses within the deposit; this generates a source of vacancies whose flow is counterbalanced by the diffusion of Sn atoms, which provides the means for whisker formation and growth. On this basis, increased resistance to whisker formation may be derived from an increase in the thickness of the surface oxide, i.e. the increased thickness of the oxide film makes it more difficult for localised breakage of the oxide film to occur. Evidence that increased oxide thickness can make whisker growth more difficult has been observed in the current study from a $1 \mu \mathrm{m}$ Sn-Cu deposit electrochemically oxidised for different times (Figure 20). However, interpretation of the results is potentially complicated by dissolution of the Sn deposit that 
occurred during electrochemical oxidation at $-0.66 \mathrm{~V}$ vs. SCE. This results in a reduction in the thickness of the Sn deposit, the extent of which increases with increasing oxidation time. A reduction in deposit thickness may potentially result in an increased susceptibility to whisker growth [18,30-32], however, at thicknesses $<1 \mu \mathrm{m}$ the effect on whisker growth it not so well established. Ideally, an electrochemical oxidation treatment that did not result in pronounced Sn dissolution would be preferable.

Although whisker densities were greatly reduced on all of the electrochemically oxidised samples, whiskers were still observed even on the samples oxidised for $30 \mathrm{~min}$, however, as shown in Figure 21, these were often growing from regions of the deposit that were discernibly less oxidised than the surrounding regions, i.e. areas that, potentially, represent a weak-point within the oxide film. It may be inferred, however, that the increase in oxide thickness on the electrochemically oxidised $\mathrm{Sn}-\mathrm{Cu}$ deposits on $\mathrm{Cu}$, in particular those oxidised at $1.2 \mathrm{~V}$ (vs. SCE), results in fewer weak points in the surface oxide and hence a reduced propensity for whisker growth.

In terms of long term whisker mitigation, the increased thickness of the oxide film may simply increase the incubation period prior to the onset of whisker growth since increased levels of compressive stress, brought about by intermetallic formation within the $\mathrm{Sn}-\mathrm{Cu}$ coating [28] and at the coating-substrate interface [13], will be required to initiate oxide film cracking and subsequent whisker growth [1]. To address this issue, and also to further evaluate the comparative effectiveness of oxide films produced in borate buffer and potassium bicarbonate-carbonate electrolyte solutions, long term whisker density measurements will be carried out. 


\section{Conclusions}

For the first time, a direct correlation has been demonstrated between oxide thickness and whisker growth. Significantly reduced whisker growth has been observed for both pure Sn deposits on brass and Sn-Cu deposits on Cu that were electrochemically oxidised shortly after deposition.

For electroplated Sn on brass, whisker growth is mitigated by the formation of a comparatively thick Sn oxide on the surface of the Sn deposit, which prevents the formation of Zn oxide on the surface of the deposit, in particular at the Sn grain boundaries.

For $\mathrm{Sn}-\mathrm{Cu}$ deposits on $\mathrm{Cu}$, reduced whisker growth simply results from the increased thickness of the oxide film, which, potentially, makes localised cracking of the oxide film more difficult to achieve.

The thickness of the oxide films developed by electrochemical oxidation was dependent upon the applied potential and the total charge passed. Comparable reductions in whisker growth were observed for borate buffer and potassium bicarbonate-carbonate electrolyte solutions.

\section{Acknowledgements}

The authors would like to thank the UK EPSRC Innovative Electronics Manufacturing Research Centre for funding this research through the WHISKERMIT programme and also Loughborough University Materials Research School for provision of a student bursary for one of the authors (Dan Haspel). 


\section{References}

1. K. N. Tu, Phys. Rev. B 49, 2030 (1994).

2. K. N. Tu and K. Zeng, in Proc. IEEE Electron. Components Technol. Conf. Piscatawny, NJ, USA (2002), pp. 1194-1200.

3. K. Tu, C. Chen, and A. T. Wu, J. Mater. Sci. Mater. Electron. 18, 269 (2007).

4. K. S. Kumar, L. Reinbold, A. F. Bower, and E. Chason, J. Mater. Res. 23, 2916 (2008).

5. J. K. Shin and E. Chason, J. Mater. Res. 24, 1522 (2009).

6. E. Chason, N. Jadhav, W. L. Chan, L. Reinbold, and K. S. Kumar, Appl. Phys. Lett. 92, 171901 (2008).

7. B. Z. Lee and D. N. Lee, Acta Mater. 46, 3701 (1998).

8. C. Y. Chang and R. W. Vook, Thin Solid Films 228, 205 (1993).

9. K. W. Moon, C. E. Johnson, M. E. Williams, O. Kongstein, G. R. Stafford, C. A. Handwerker, and W. J. Boettinger, J. Electron. Mater. 34, L31 (2005).

10. N. Jadhav, E. Buchovecky, E. Chason, and A. Bower, JOM 62, 30 (2010).

11. B. Jiang and A. P. Xian, Philos. Mag. Lett. 86, 521 (2006).

12. K. Suganuma, A. Baated, K.-S. Kim, K. Hamasaki, N. Nemoto, T. Nakagawa, and T. Yamada, Acta Mater. 59, 7255 (2011).

13. K. N. Tu, Acta Metall. 21, 347 (1973).

14. R. Díaz, I. Díez-pérez, P. Gorostiza, F. Sanz, and J. R. Morante, J. Braz.chem. Soc. 14, 523 (2003).

15. S. D. Kapusta and N. Hackerman, Electrochim. Acta 25, 1625 (1980).

16. P. E. Alvarez, S. B. Ribotta, M. E. Folquer, C. A. Gervasi, and J. R. Vilche, Corros. Sci. 44, 49 (2002).

17. M. Drogowska, H. Menard, and L. Brossard, J. Appl. Electrochem. 21, 84 (1991).

18. M. A. Ashworth, G. D. Wilcox, R. L. Higginson, R. J. Heath, and C. Liu, Trans. Inst. Met. Finish. 91, 260 (2013).

19. D. Morgan Tench, D. P. Anderson, and P. Kim, J. Appl. Electrochem. 24, 18 (1994).

20. G. Schon, J. Electron Spectros. Relat. Phenomena 2, 75 (1973). 
21. K. W. Moon, M. E. Williams, C. E. Johnson, G. R. Stafford, C. A. Handwerker, and W. J. Boettinger, in Proc. PRICM4 Forth Pacific Rim Int. Conf. Adv. Mater. Process. Honolulu, Hawaii, USA. December 11-15, edited by S. Hanada, Z. Zhong, S. W. Nam, and R. N. Wright (2001), pp. 1115-1118.

22. S. N. Shah and D. Eurof Davies, Electrochim. Acta 8, 663 (1963).

23. NIST, X-Ray Photoelectron Spectrosc. Database, NIST Stand. Ref. Database 20, Version 4.1, Http//srdata.nist.gov/xps/ (n.d.).

24. W. Zhang and W. Ruythooren, in 2009 Eur. Microelectron. Packag. Conf. (EMPC 2009), VOLS 12 (2009), pp. 597-600.

25. S. C. Britton and M. Clarke, Trans. Inst. Met. Finish. 40, 205 (1964).

26. B. D. Dunn, Eur. Sp. Agency Rep. STR-223, Eur. Sp. Agency, Paris, Fr. (1987).

27. S. Sakuyama and M. Kutami, FUJITSU Sci. Tech. J. 41, 217 (2005).

28. W. J. Boettinger, C. E. Johnson, L. A. Bendersky, K. W. Moon, M. E. Williams, and G. R. Stafford, Acta Mater. 53, 5033 (2005).

29. M. E. Williams, K. W. Moon, W. J. Boettinger, D. Josell, and A. D. Deal, J. Electron. Mater. 36, 214 (2007).

30. M. Dittes, P. Oberndorff, and L. Petit, in 53rd Electron. Components Technol. Conf. 2003 Proc. (2003), pp. 822-826.

31. J. Cheng, F. Yang, P. T. Vianco, B. Zhang, and J. C. M. Li, J. Electron. Mater. 40, 2069 (2011).

32. E. R. Crandall, Factors Governing Tin Whisker Growth, PhD thesis, Auburn University, 2012. 
Figure 1 Cyclic voltammetry for $10 \mu \mathrm{m}$ Sn electrodeposits on $\mathrm{Cu}$ at a sweep rate of $10 \mathrm{mV} \mathrm{s}^{-1}$ in: (a) $\mathrm{pH} 8.4$ borate buffer electrolyte solution and (b) $\mathrm{pH} 8.9$ potassium bicarbonatecarbonate electrolyte solution

Figure 2 Current-time curves for electrochemical oxidation of Sn deposits on $\mathrm{Cu}$ in potassium bicarbonate/carbonate electrolyte solution at different potentials (V vs. SCE)

Figure 3 High resolution XPS scans of the Sn 3d peak for $2 \mu \mathrm{m}$ Sn on brass deposits 1 day after deposition and electrochemical oxidation in a potassium bicarbonate/carbonate electrolyte solution: (a) native air-formed oxide, (b) electrochemical oxidation at $-0.83 \mathrm{~V}$, (c) $-0.66 \mathrm{~V}$, (d) $-0.5 \mathrm{~V}$, (e) $0.35 \mathrm{~V}$ and (f) $1.2 \mathrm{~V}$ (vs. SCE)

Figure 4 XPS depth profiles for oxygen showing the effect of time on oxide thickness for Sn electrodeposits on copper oxidised in potassium bicarbonate-carbonate electrolyte solution at $-0.66 \mathrm{~V}$ vs. SCE. The inset secondary electron images show the effect of increasing oxidation time on the surface of the Sn deposit.

Figure 5 High resolution XPS scans of the Sn 3d peak for $2 \mu \mathrm{m}$ Sn on brass deposits 1 day after deposition and electrochemical oxidation in a $\mathrm{pH} 8.4$ borate buffer electrolyte solution: (a) $1.2 \mathrm{~V}$ vs. SCE, (b) $1.6 \mathrm{~V}$ vs. SCE and (c) $2.0 \mathrm{~V}$ vs. SCE

Figure 6 XPS depth profiles showing the effect of sample treatment on oxide thickness and elemental distribution at the surface of $2 \mu \mathrm{m}$ Sn deposits on brass one day after deposition (a) electrochemical oxidation, at $1.2 \mathrm{~V}$ vs. SCE in potassium bicarbonate-carbonate electrolyte solution, (b) electrochemical oxidation, at 1.2 V vs. SCE in pH 8.4 borate buffer electrolyte solution and (c) a native air-formed oxide

Figure 7 Electrochemical reduction curves showing effect of storage time on the development of the surface oxide for $2 \mu \mathrm{m}$ Sn deposits on brass. Electrochemical reduction in naturally aerated pH 8.4 borate buffer electrolyte solution at $60 \mu \mathrm{A} \mathrm{cm}{ }^{-2}$ 
Figure 8 XPS depth profiles showing the effect of electrochemical oxidation on oxide thickness and elemental distribution at the surface of $2 \mu \mathrm{m}$ Sn deposits on brass $\sim 300$ days after deposition: (a) native air-formed oxide and (b) electrochemical oxidation at $1.2 \mathrm{~V}$ vs. SCE in a pH 8.4 borate buffer electrolyte solution.

Figure 9 High resolution scan of the Sn 3d peak after sputtering for $210 \mathrm{~s}$ to the position at which the maximum Zn concentration is observed. XPS analysis 300 days after deposition and subsequent electrochemical oxidation at $1.2 \mathrm{~V}$ vs. SCE in pH 8.4 borate buffer electrolyte solution.

Figure 10 Secondary electron images comparing the surface morphology of $2 \mu \mathrm{m}$ Sn on brass deposits 270 days after deposition: (a) sample left to develop native air-formed oxide, (b), (c) and (d) electrochemical oxidation in pH 8.4 borate buffer electrolyte solution at $1.2 \mathrm{~V}$, 1.6 V and 2.0 V vs. SCE, respectively

Figure 11 SEM/EDS analysis of $5 \mu \mathrm{m}$ Sn deposit on brass left to develop a native air-formed oxide. Analysis 330 days after deposition: (a) secondary electron image of deposit surface, (b) Sn L $\alpha$ x-ray map, (c) Zn Ka x-ray map and (d) O Ka x-ray map

Figure 12 Secondary electron images showing examples of whisker growth on a $2 \mu \mathrm{m}$ Sn deposits on brass left to develop a native air-formed oxide. Analysis 300 days after deposition

Figure 13 SEM analysis of $2 \mu \mathrm{m}$ Sn deposit on brass 90 days after Ar ion sputtering to remove the electrochemically oxidised surface (1.2 V vs. SCE in borate buffer electrolyte solution): (a) Sn L $\alpha$ x-ray map, (b) $\mathrm{Zn} \mathrm{L \alpha ,} \mathrm{(c)} \mathrm{O} \mathrm{K \alpha ,} \mathrm{(d)} \mathrm{secondary} \mathrm{electron} \mathrm{image} \mathrm{of} \mathrm{mapped}$ region, (e) secondary electron image showing region 1 and (f) secondary electron image showing whisker growth in region 2 (sputtered area). Sputtering was performed 300 days after Sn deposition

Figure 14 XPS analysis of surface of a $2 \mu \mathrm{m}$ Sn-Cu electrodeposit electrochemically oxidised at $1.2 \mathrm{~V}$ vs. SCE in potassium bicarbonate-carbonate electrolyte solution after storage at 
room temperature for 21 days; (a) survey scan and inset (b) high resolution scan of the Cu 3p peak

Figure 15 XPS depth profiles for oxygen comparing the thickness of a native air-formed oxide with oxides formed electrochemically at 1.2 V vs. SCE in borate buffer (pH 8.4) and potassium bicarbonate-carbonate electrolyte solutions. Analysis of Sn-Cu deposits on $\mathrm{Cu}, 21$ days after electroplating and electrochemical oxidation.

Figure 16 Secondary electron images showing examples of filament whisker growth on $2 \mu \mathrm{m}$ Sn-Cu deposits on Cu: (a) sample left to develop a native air-formed oxide, (b) sample electrochemically oxidised in potassium bicarbonate-carbonate electrolyte solution at $1.2 \mathrm{~V}$ vs. SCE and (c) sample electrochemically oxidised in borate buffer electrolyte solution at 1.2 V vs. SCE. Analysis 48 days after Sn-Cu deposition

Figure 17 Whisker growth data for $2 \mu \mathrm{m}$ Sn-Cu $\left(10 \mathrm{mmol} \mathrm{l}^{-1} \mathrm{Cu}\right)$ deposits on $\mathrm{Cu}, 60$ days and 180 days after deposition and electrochemical oxidation at $1.2 \mathrm{~V}$ vs. SCE in borate buffer and potassium bicarbonate-carbonate electrolyte solutions

Figure 18 Secondary electron images comparing whisker growth on $2 \mu \mathrm{m}$ Sn-Cu deposits on $\mathrm{Cu}$ (a) sample left to develop a native air-formed oxide, (b) sample electrochemically oxidised in borate buffer electrolyte solution at 1.2 V vs. SCE. Analysis 150 days after SnCu deposition

Figure 19 Image showing the geometry and surface appearance of $1 \mu \mathrm{m}$ Sn-Cu deposit on $\mathrm{Cu}$ after electrochemical oxidation in a potassium bicarbonate-carbonate electrolyte solution at $0.66 \mathrm{~V}$ vs. SCE for 5, 20 and $30 \mathrm{~min}$

Figure 20 Graph showing whisker densities measured after storage at room temperature for 60 days on a $1 \mu \mathrm{m}$ Sn-Cu electrodeposit on $\mathrm{Cu}$, electrochemically oxidised in potassium bicarbonate-carbonate electrolyte solution at $-0.66 \mathrm{~V}$ vs. SCE 
Figure 21 Secondary electron images showing whisker growth from a $1 \mu \mathrm{m} \mathrm{Sn}-\mathrm{Cu}$ electrodeposit on $\mathrm{Cu}$, after electrochemical oxidation in potassium bicarbonate-carbonate electrolyte solution at $-0.66 \mathrm{~V}$ vs. SCE for (a) $20 \mathrm{~min}$ and (b) $30 \mathrm{~min}$

Figure 22 Secondary electron images showing the surface of the $1 \mu \mathrm{m}$ Sn-Cu electrodeposit on $\mathrm{Cu}$, after electrochemical oxidation and storage at room temperature for 60 days: (a) region left to develop native air-formed oxide, (b) - (d) regions electrochemically oxidised at $-0.66 \mathrm{~V}$ vs. SCE in potassium bicarbonate-carbonate electrolyte solution for 5, 20 and $30 \mathrm{~min}$, respectively 

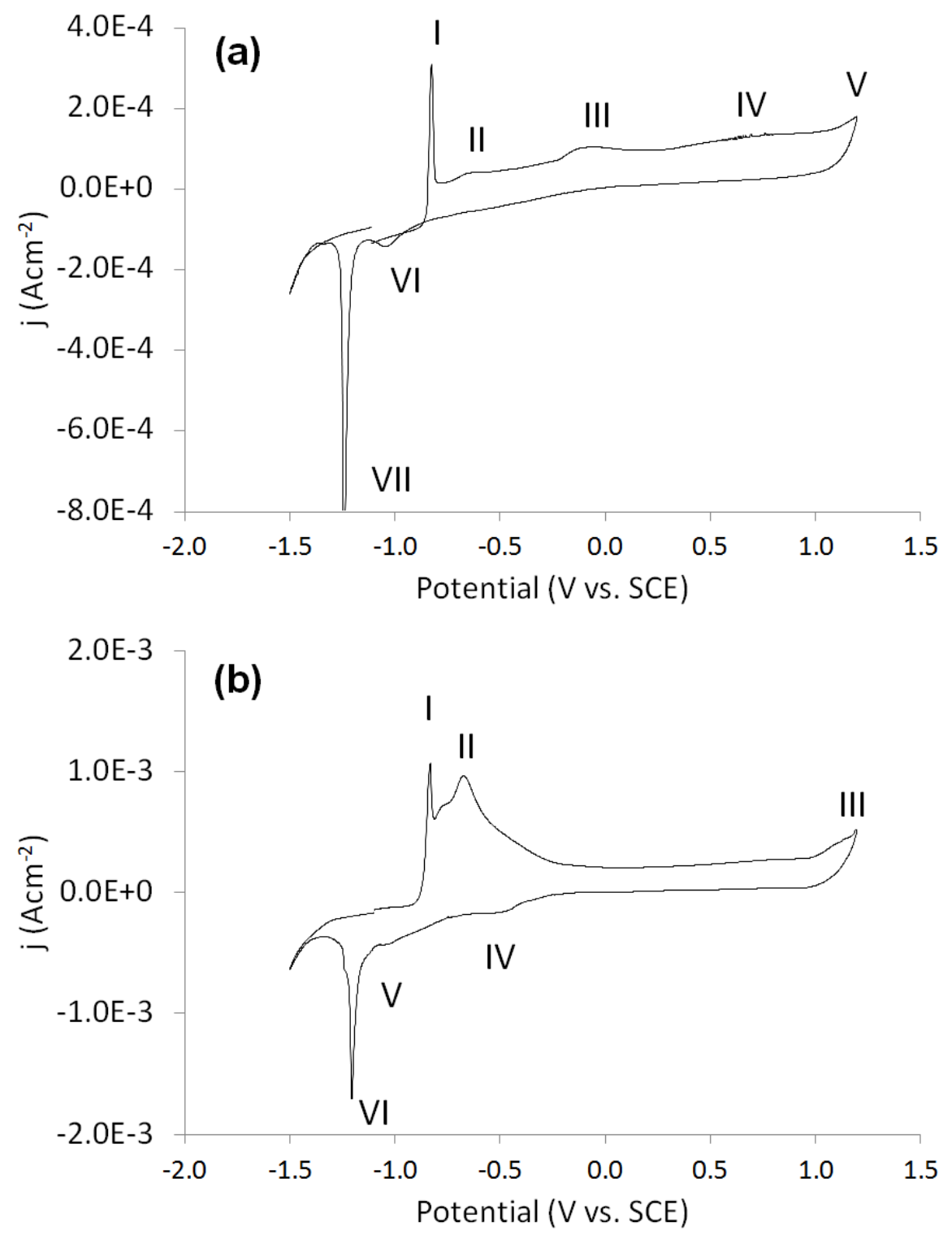

Figure 1 


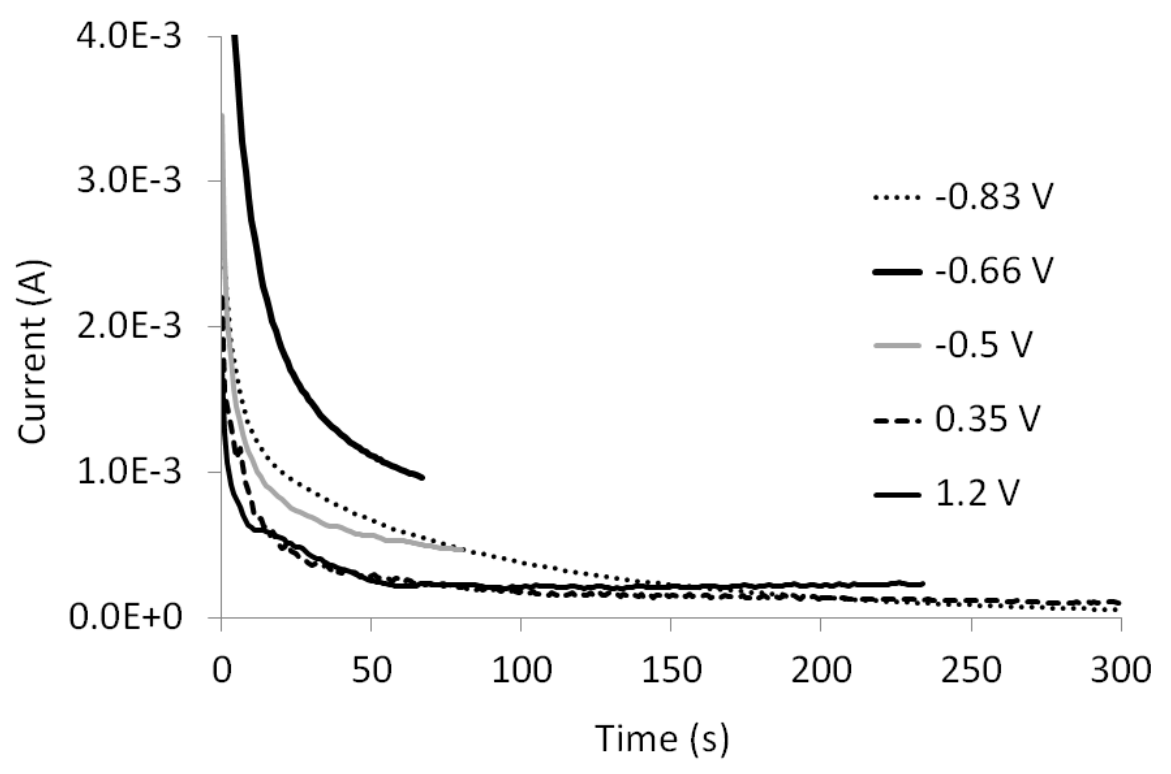

Figure 2 
(a) Native oxide

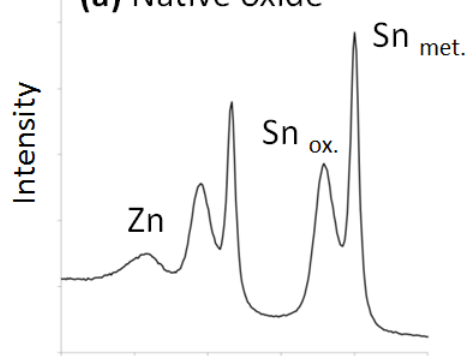

(d) $-0.5 \mathrm{~V}$

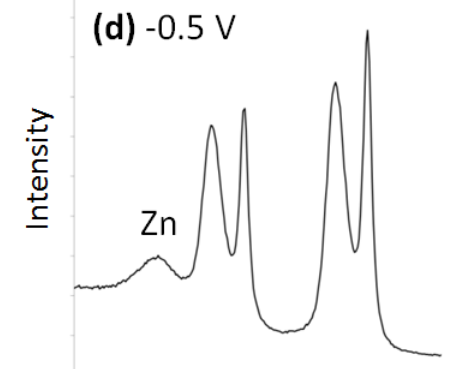

Binding energy (eV) (b) $-0.83 \mathrm{~V}$

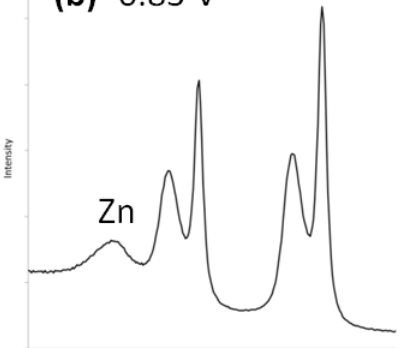

(e) $0.35 \mathrm{~V}$

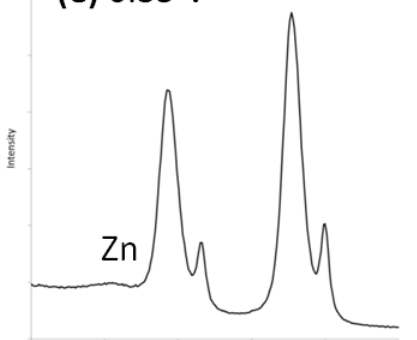

Binding energy (eV) (c) $-0.66 \mathrm{~V}$

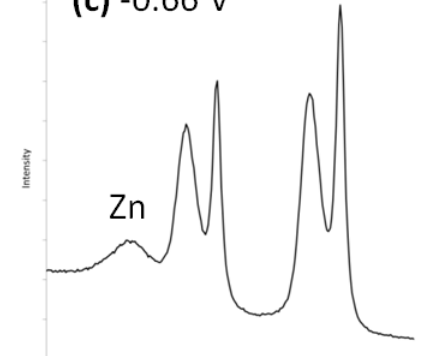

(f) $1.2 \mathrm{~V}$

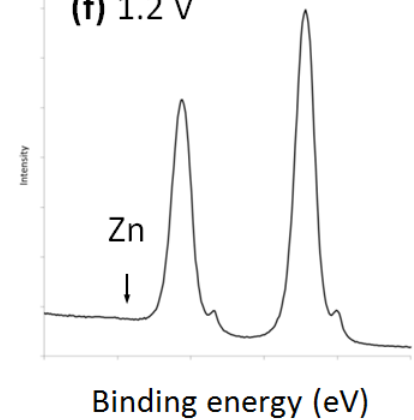

Figure 3 


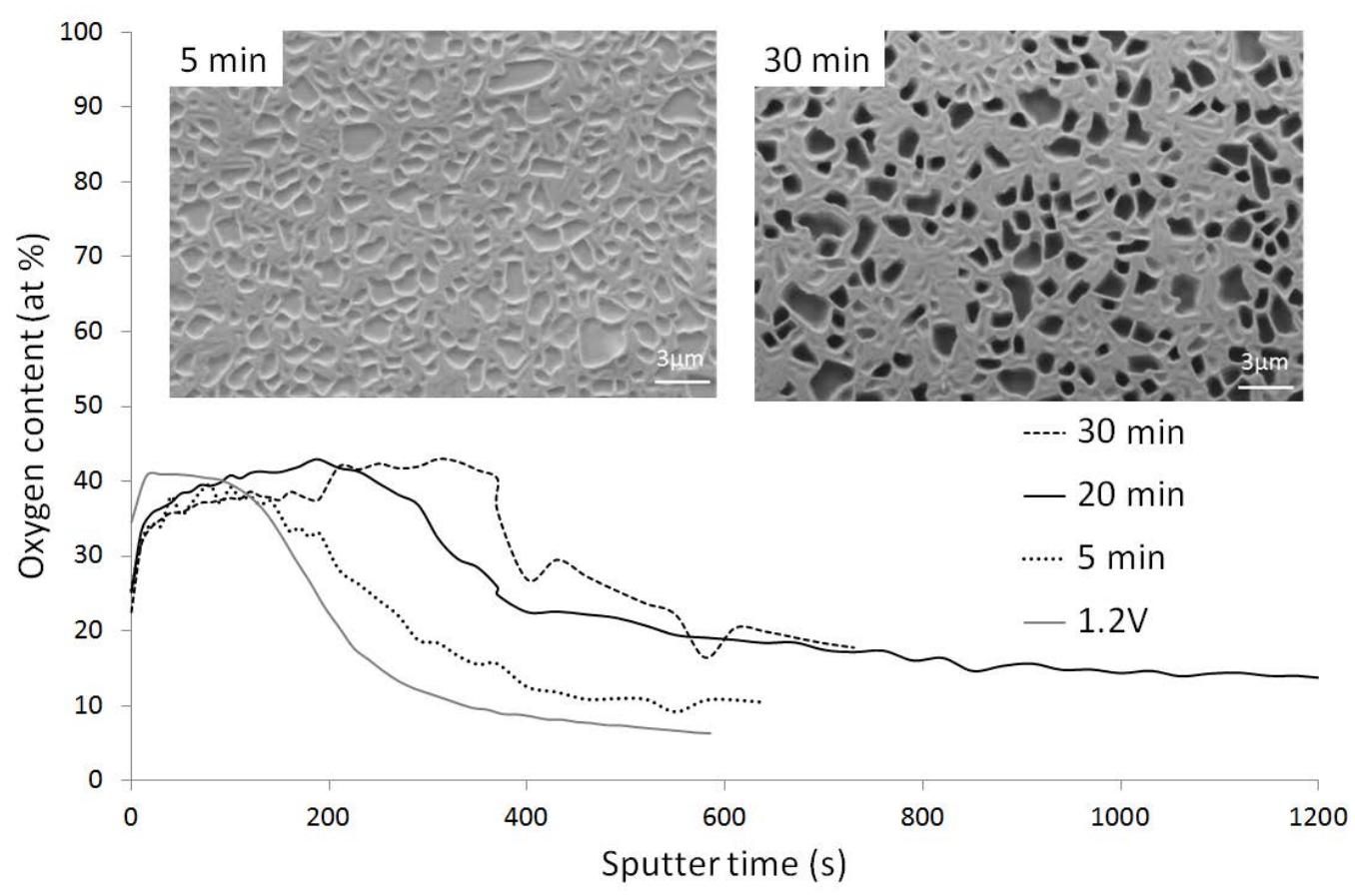

Figure 4 
(a) $1.2 \mathrm{~V}$

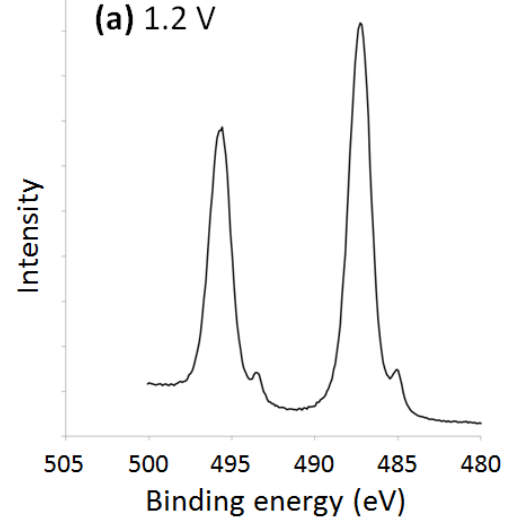

(b) $1.6 \mathrm{~V}$

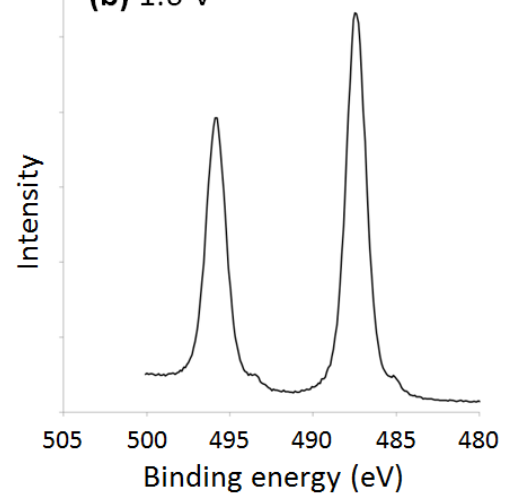

(c) $2.0 \mathrm{~V}$

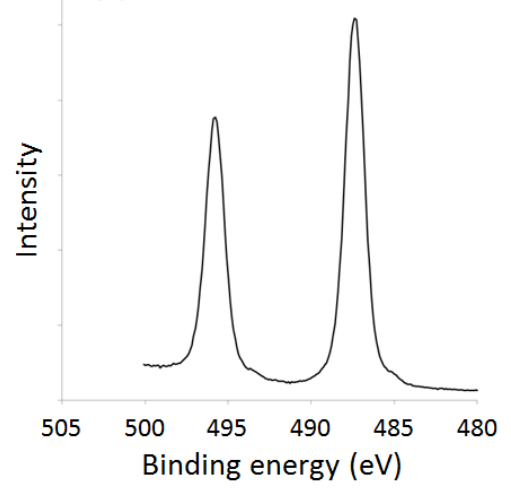

Figure 5 

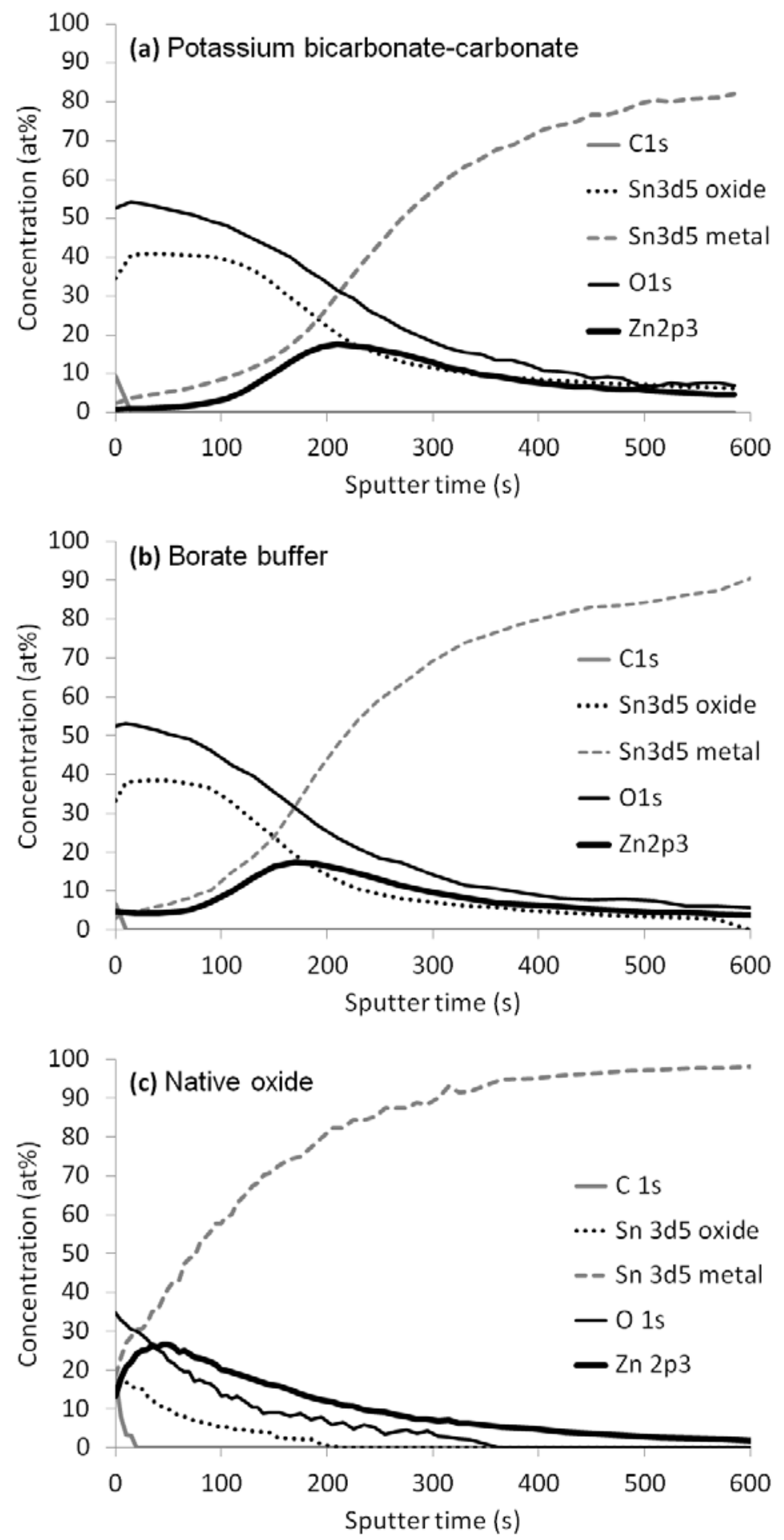

Figure 6 


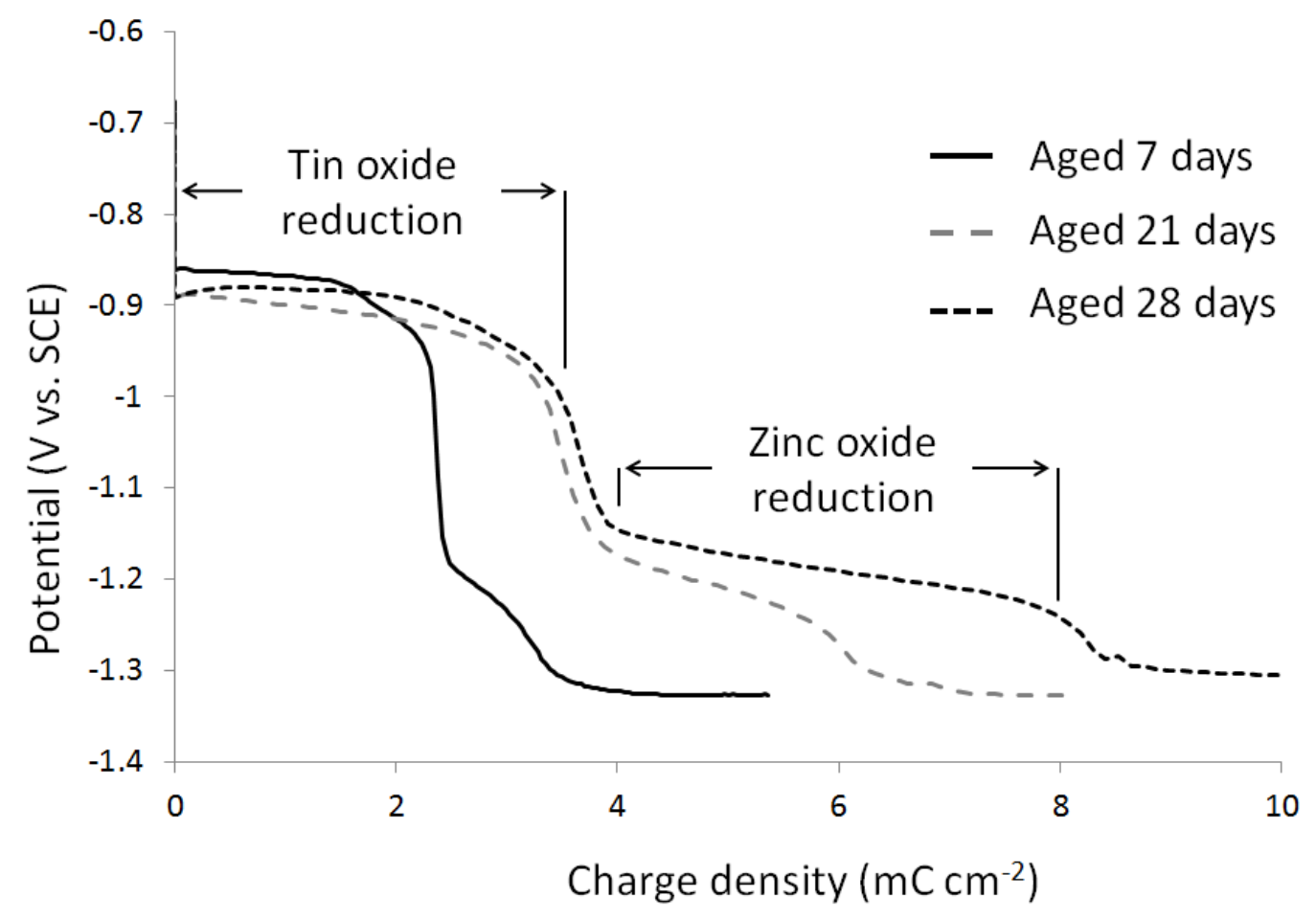

Figure 7 

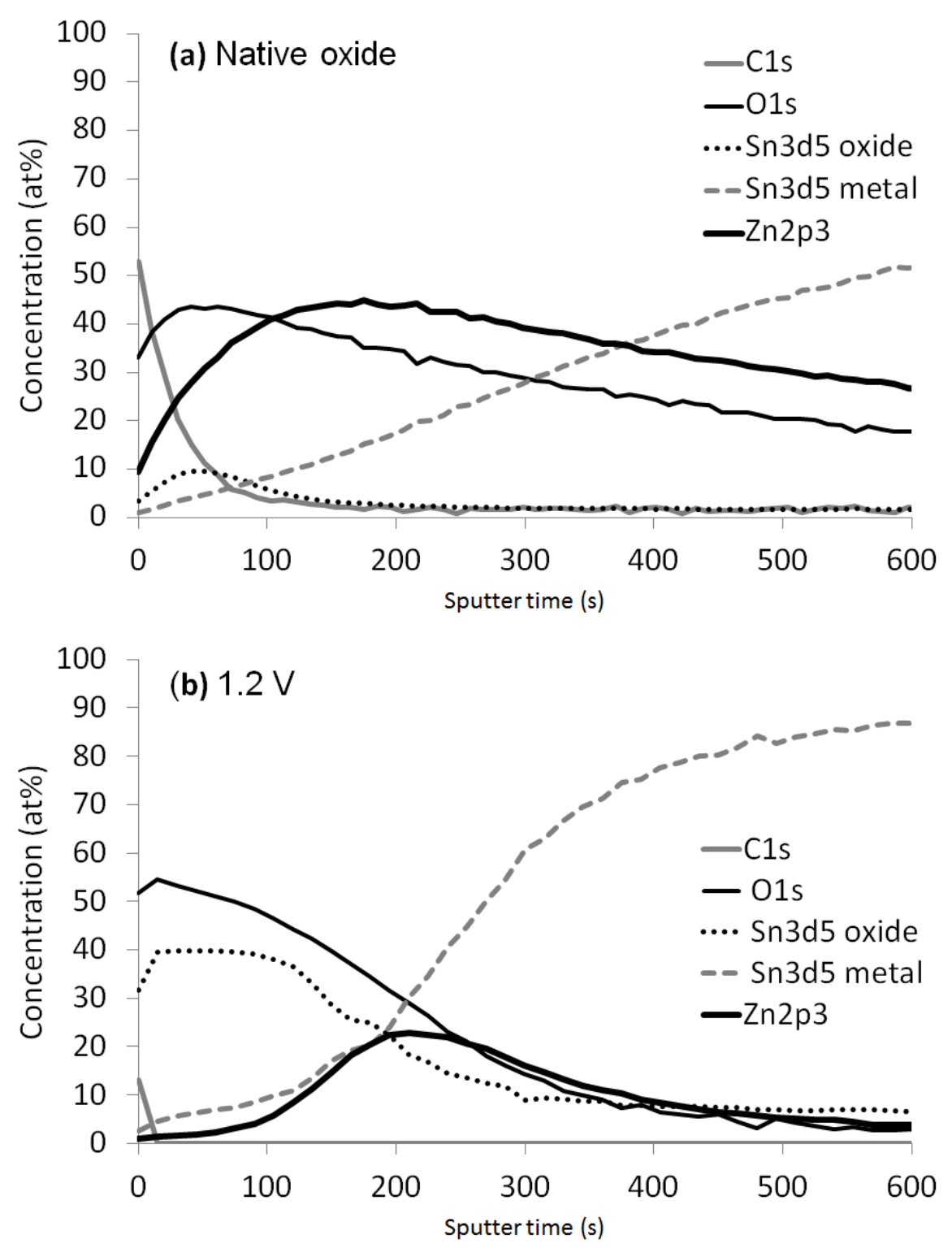

Figure 8 


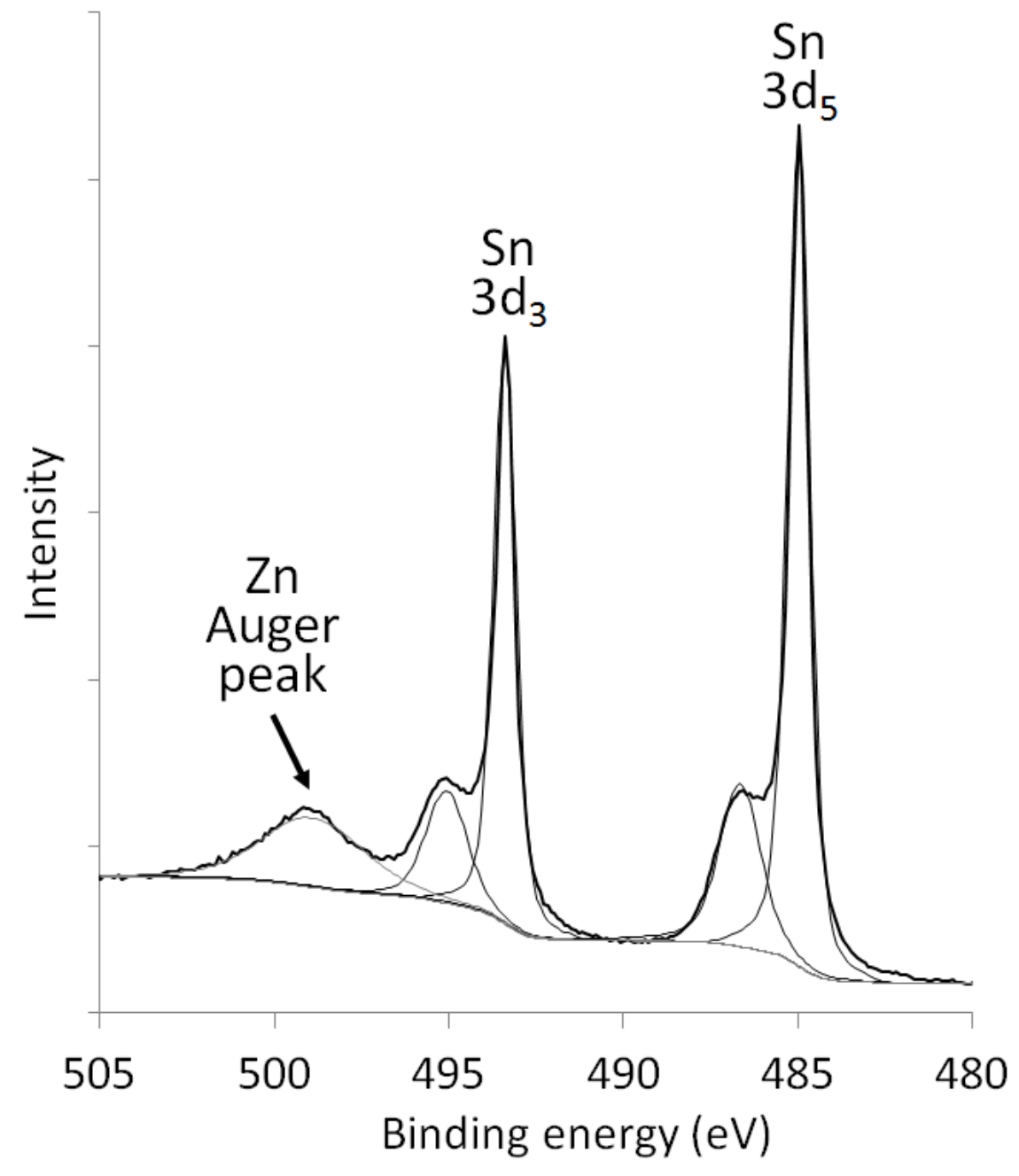

Figure 9 

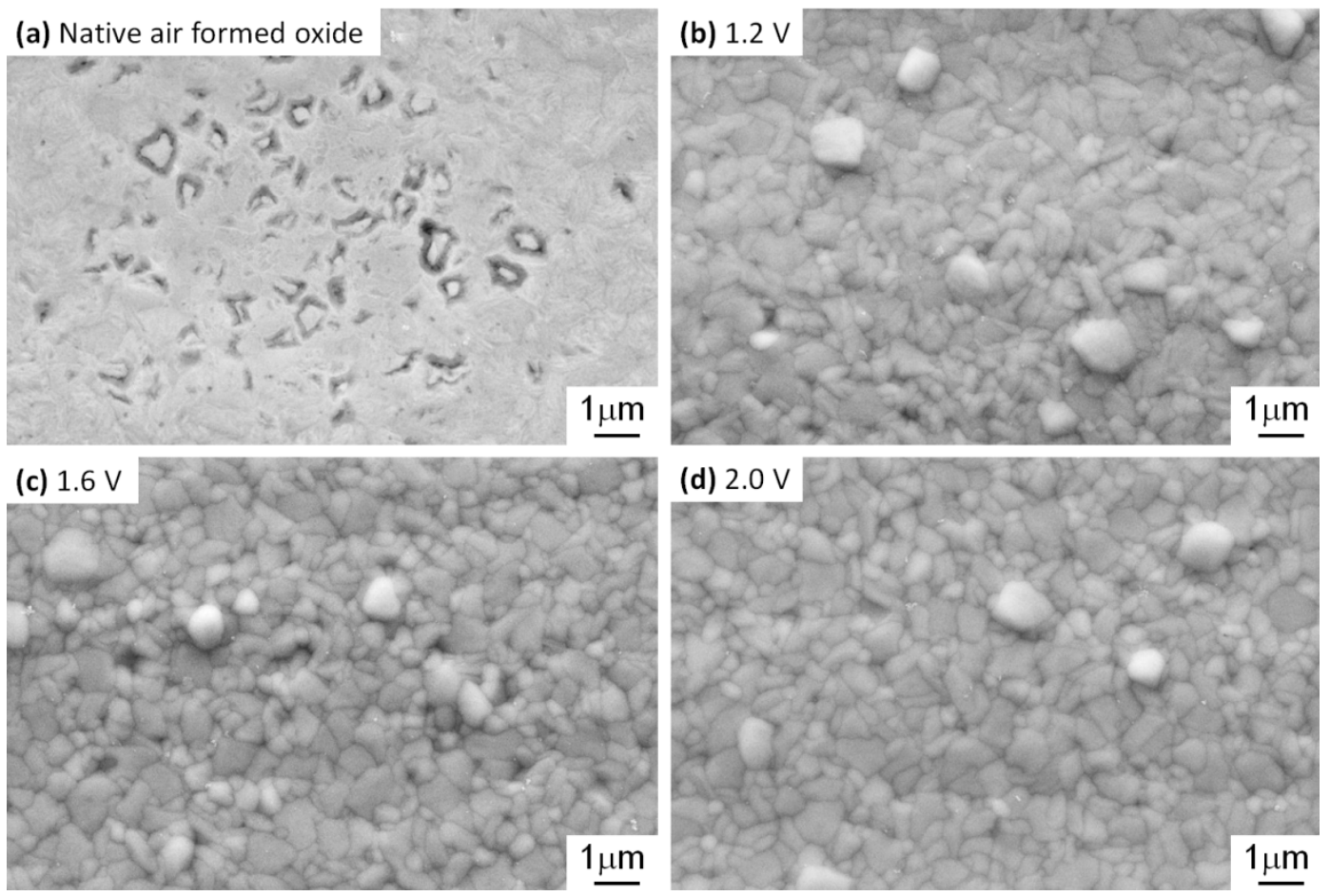

Figure 10 
(a) Secondary electron image

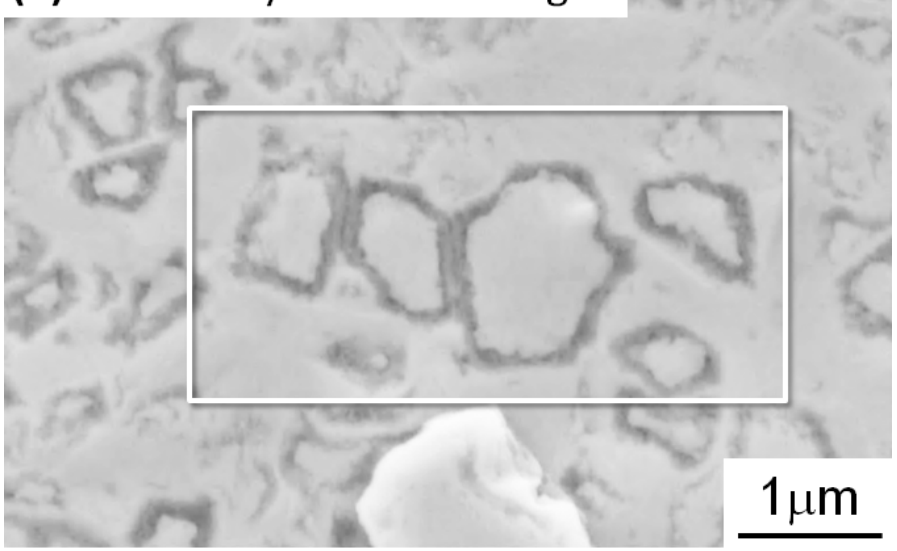

(b) Sn L $\alpha$
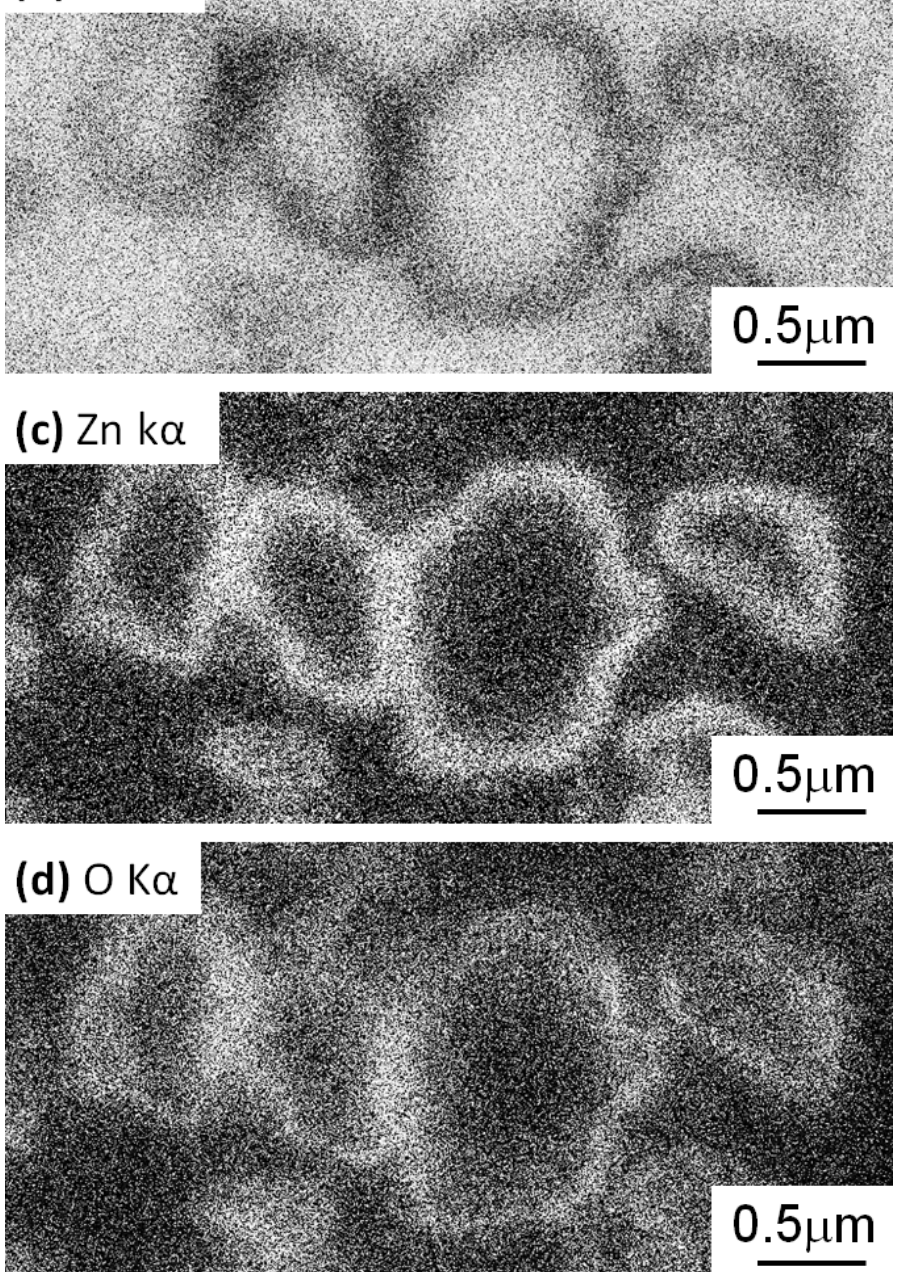

Figure 11 

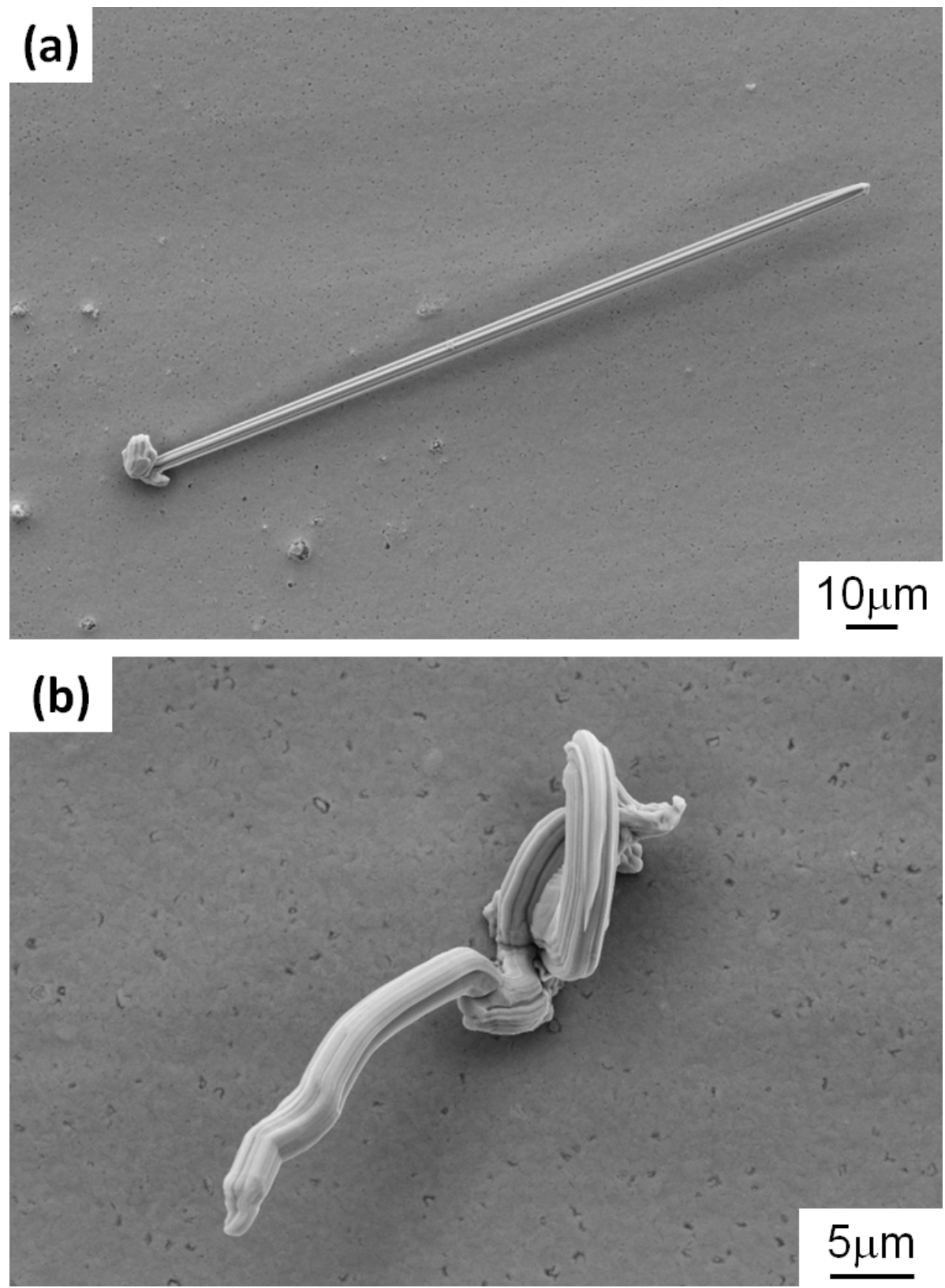

Figure 12 

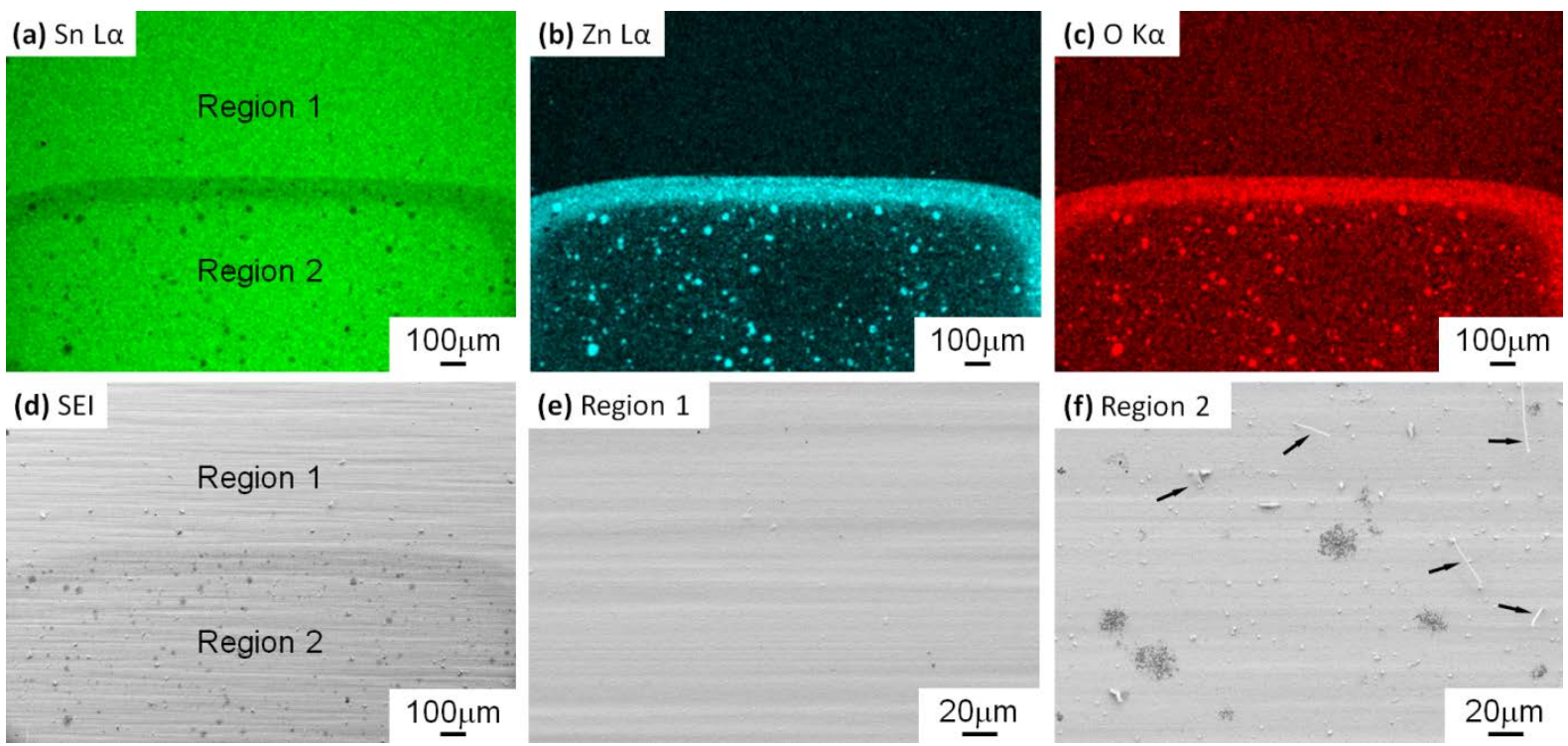

(e) Region 1

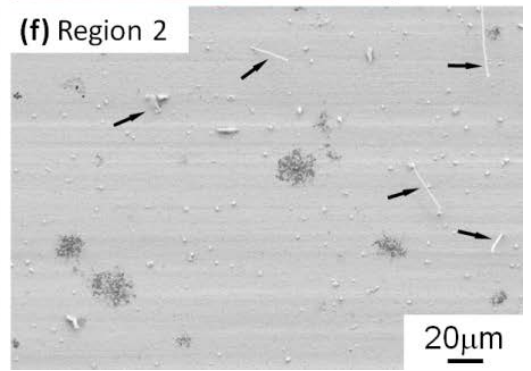

Figure 13 


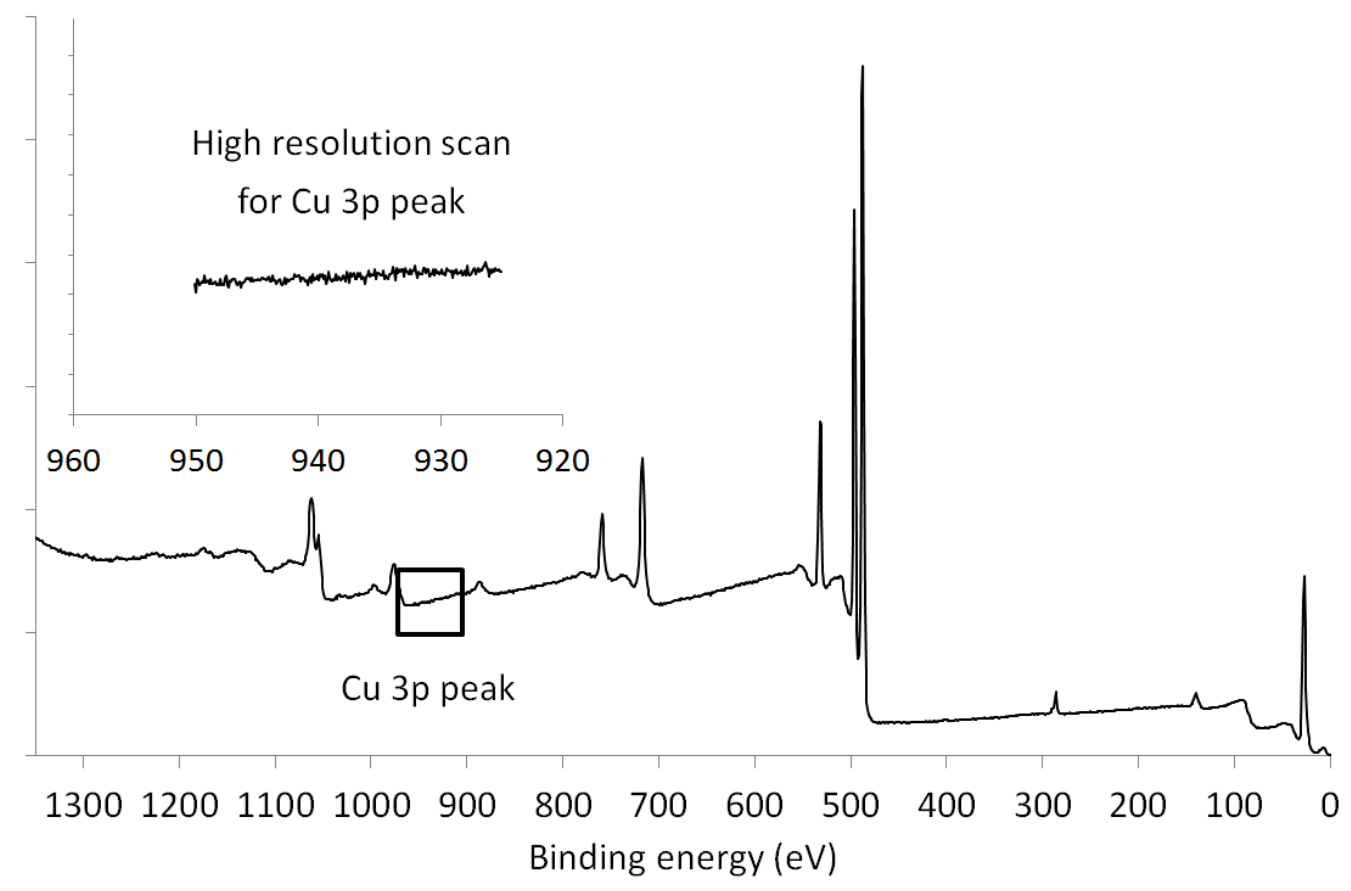

Figure 14 


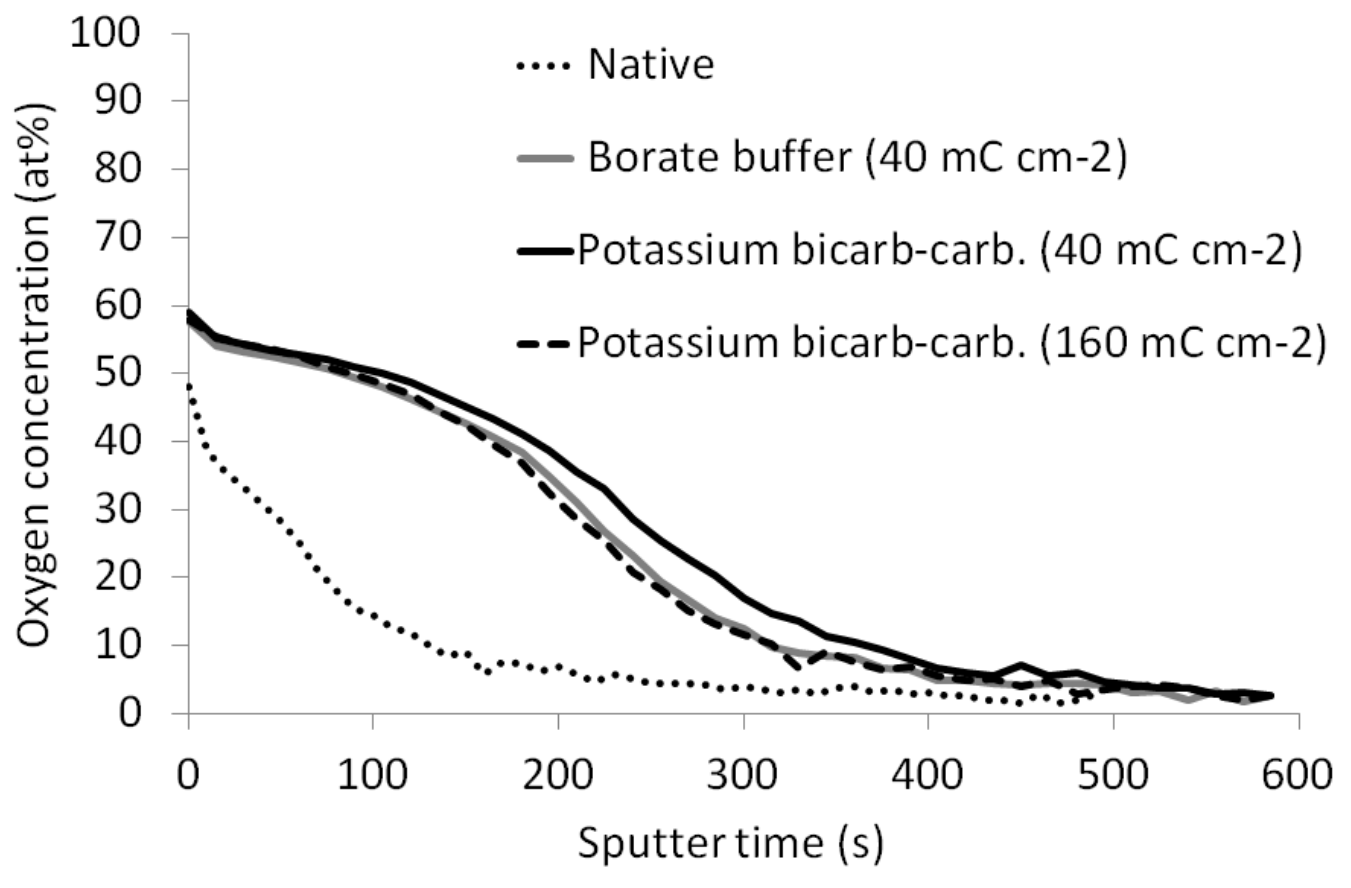

Figure 15 


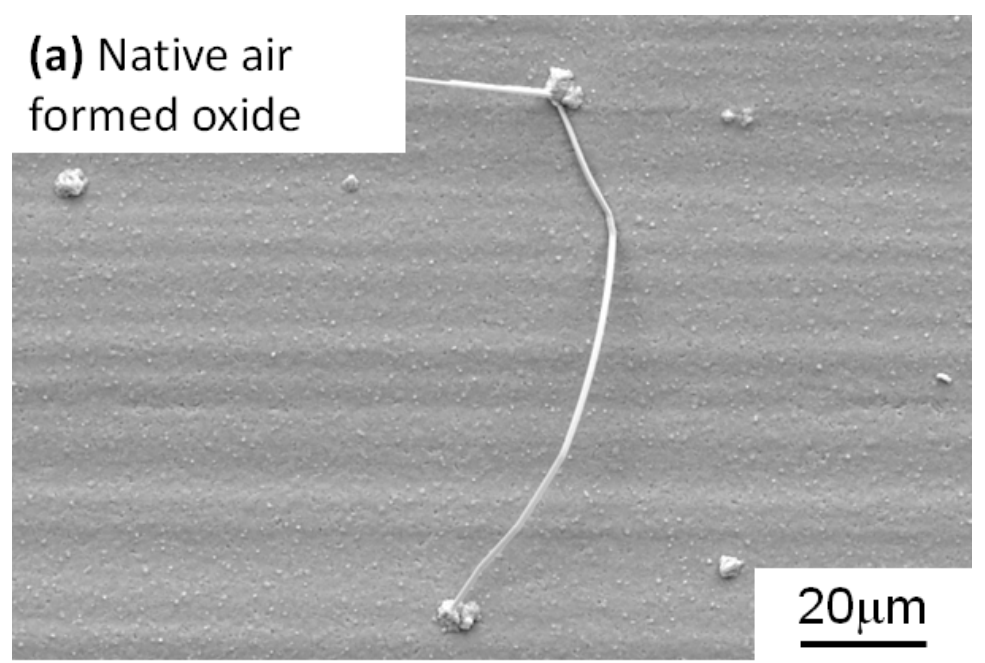

(b) Potassium bicarbonatecarbonate

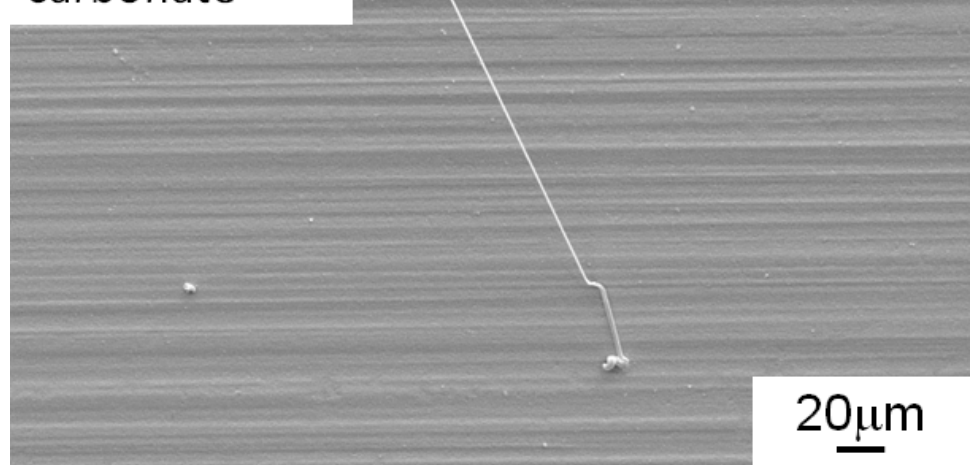

\section{(c) Borate buffer}

$20 \mu \mathrm{m}$

Figure 16 


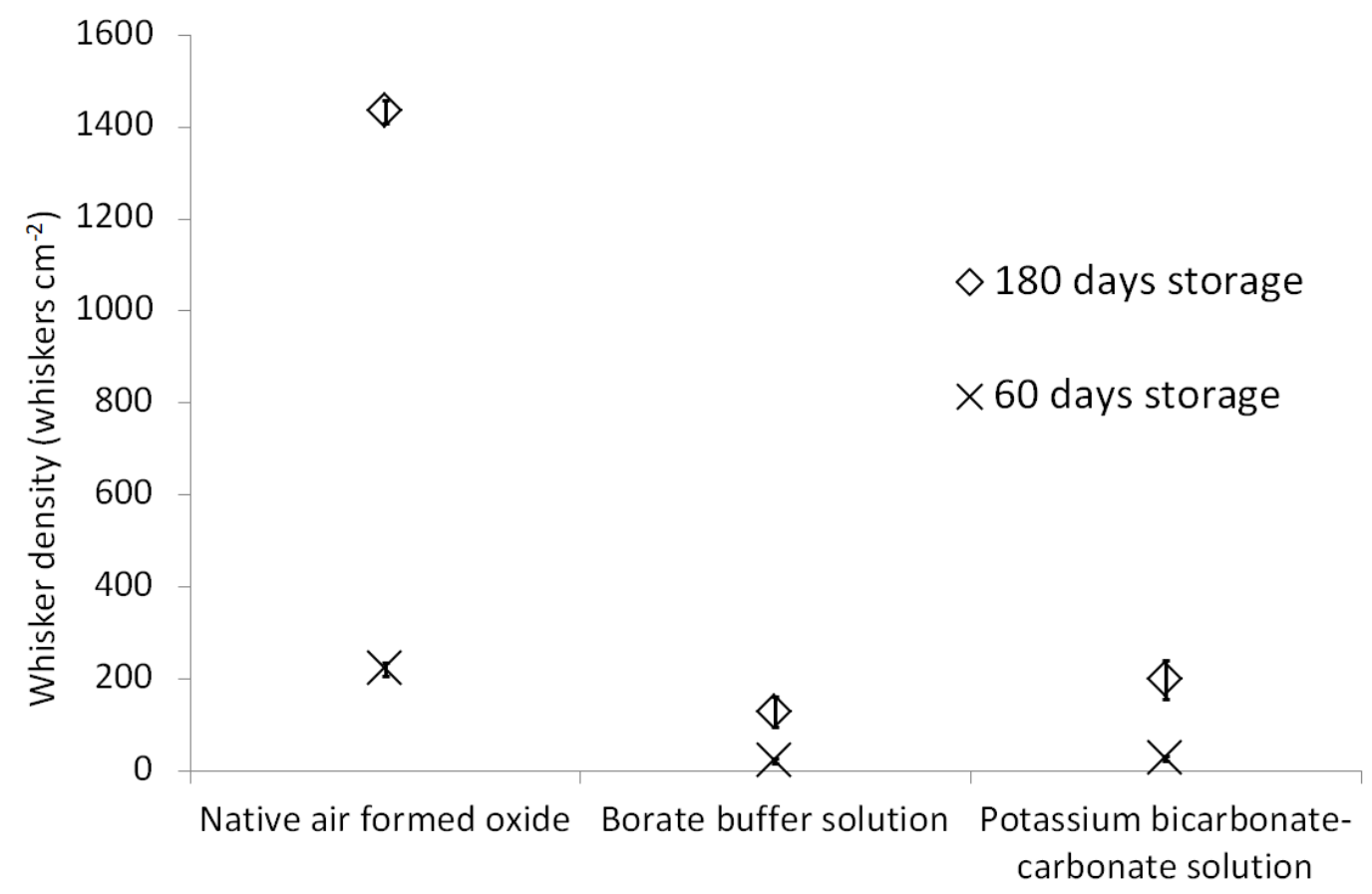

Figure 17 
(a) Native air formed oxide

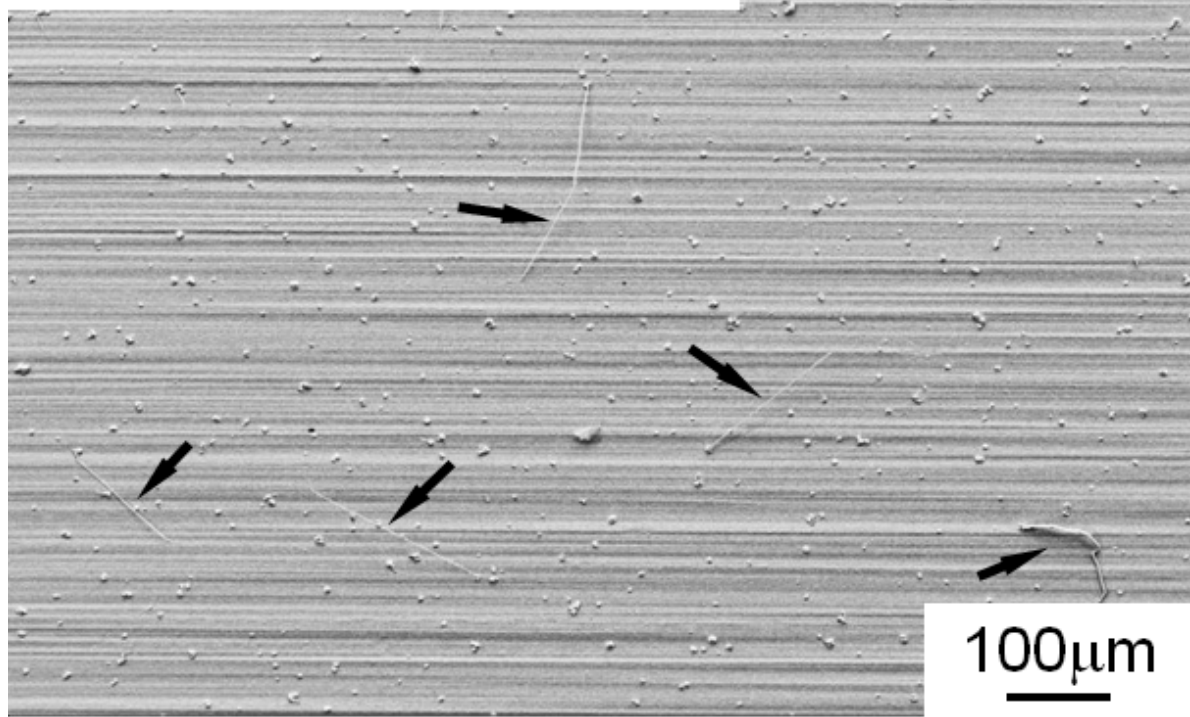

(b) Borate buffer at $1.2 \mathrm{~V}$

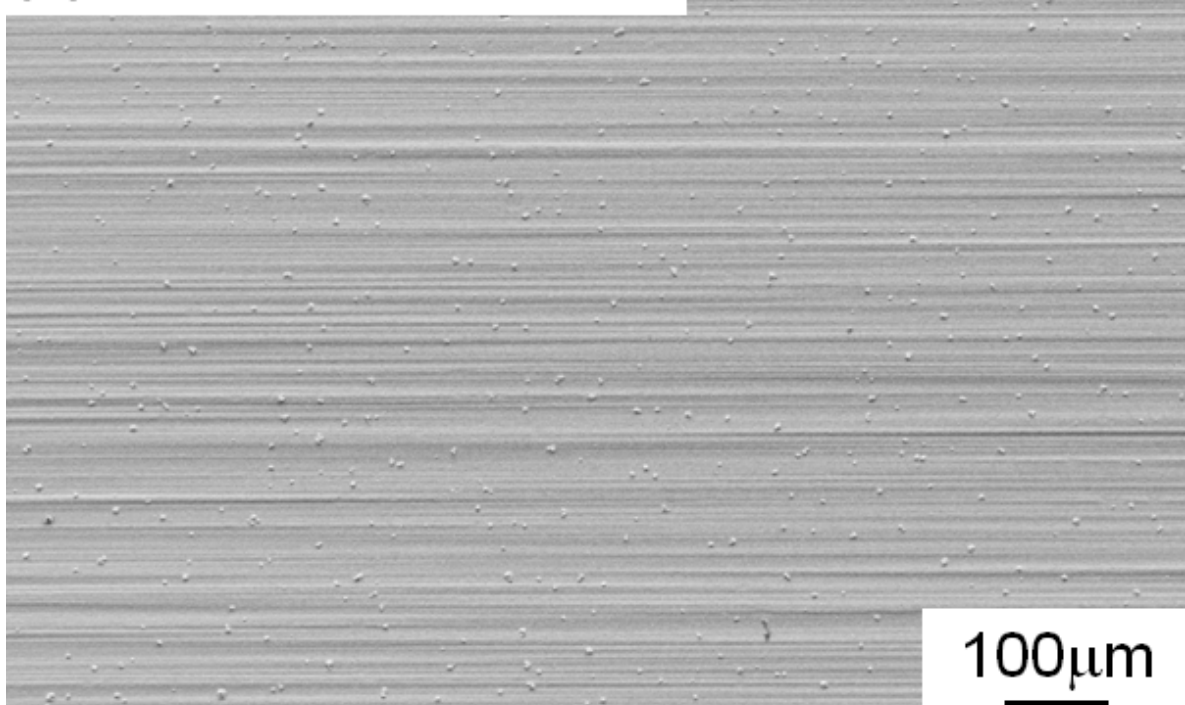

Figure 18 


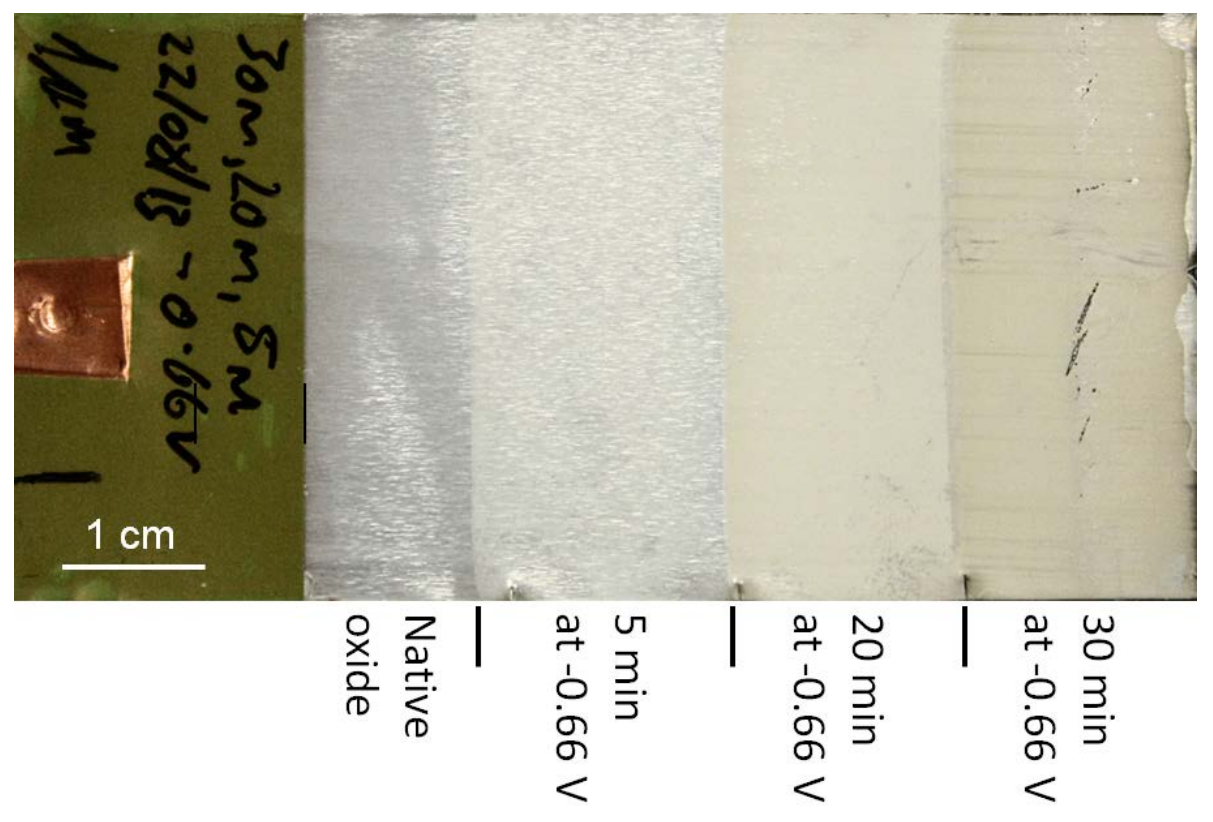

Figure 19 


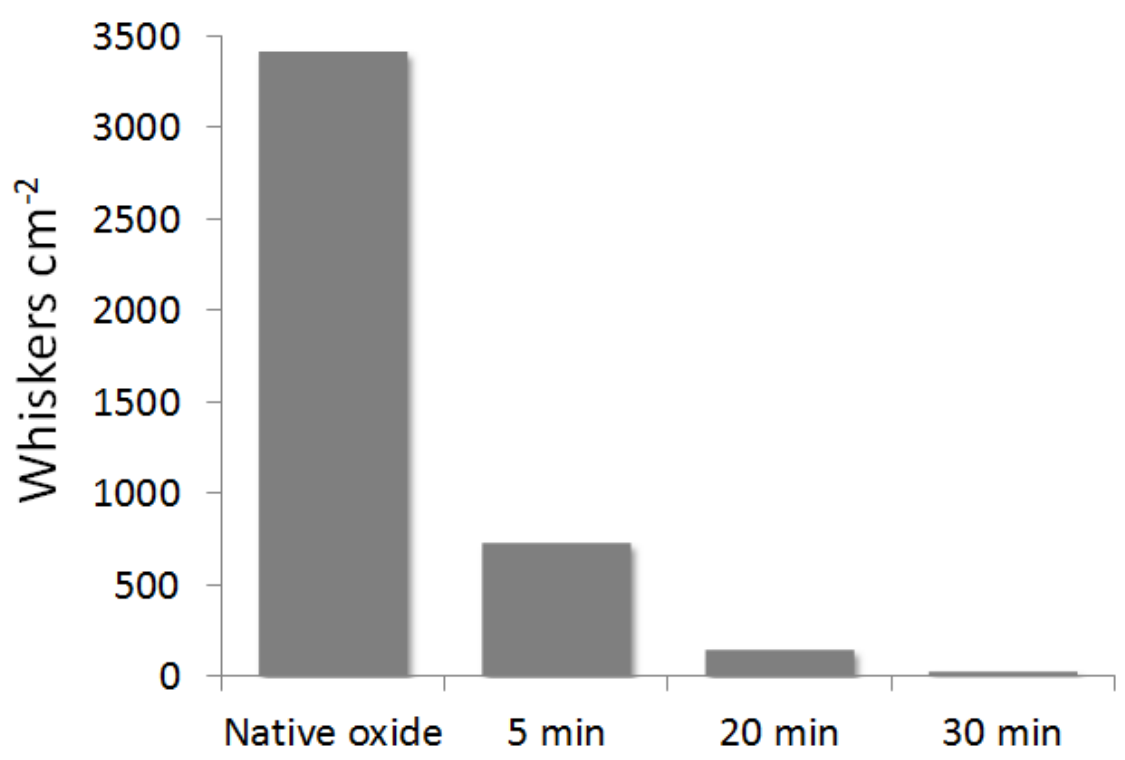

Figure 20 
(a) 20 min oxidation

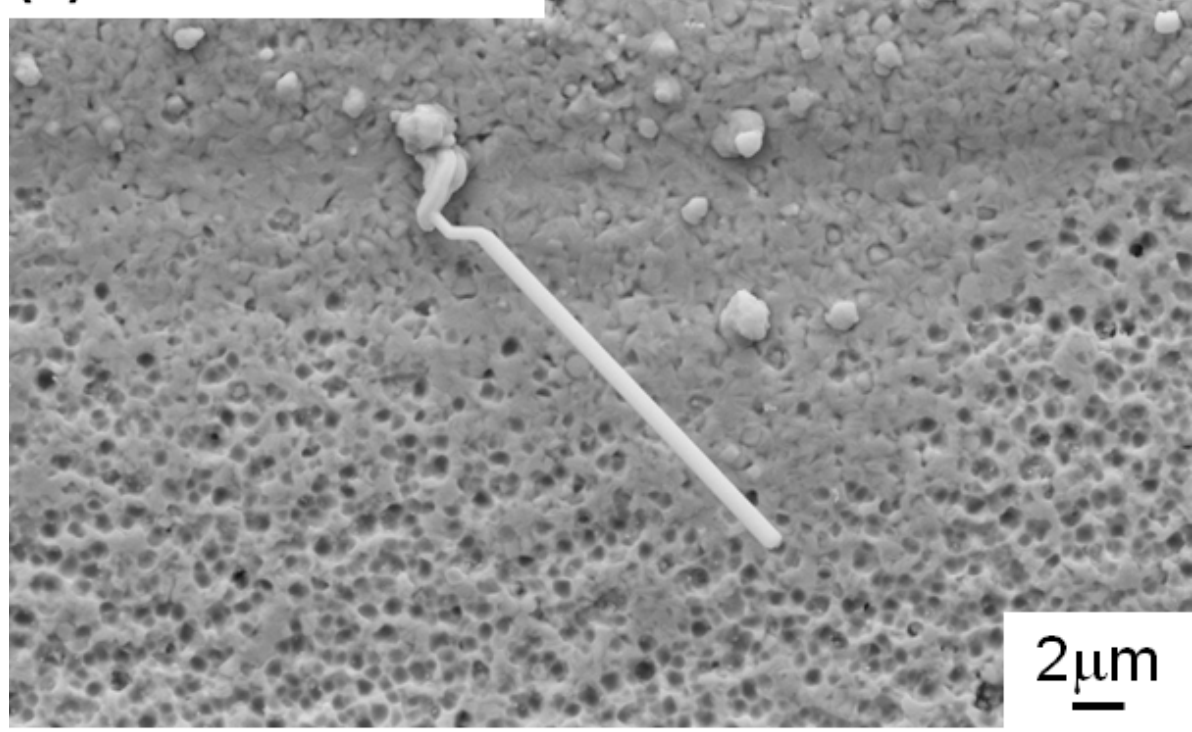

(b) 30 min oxidation

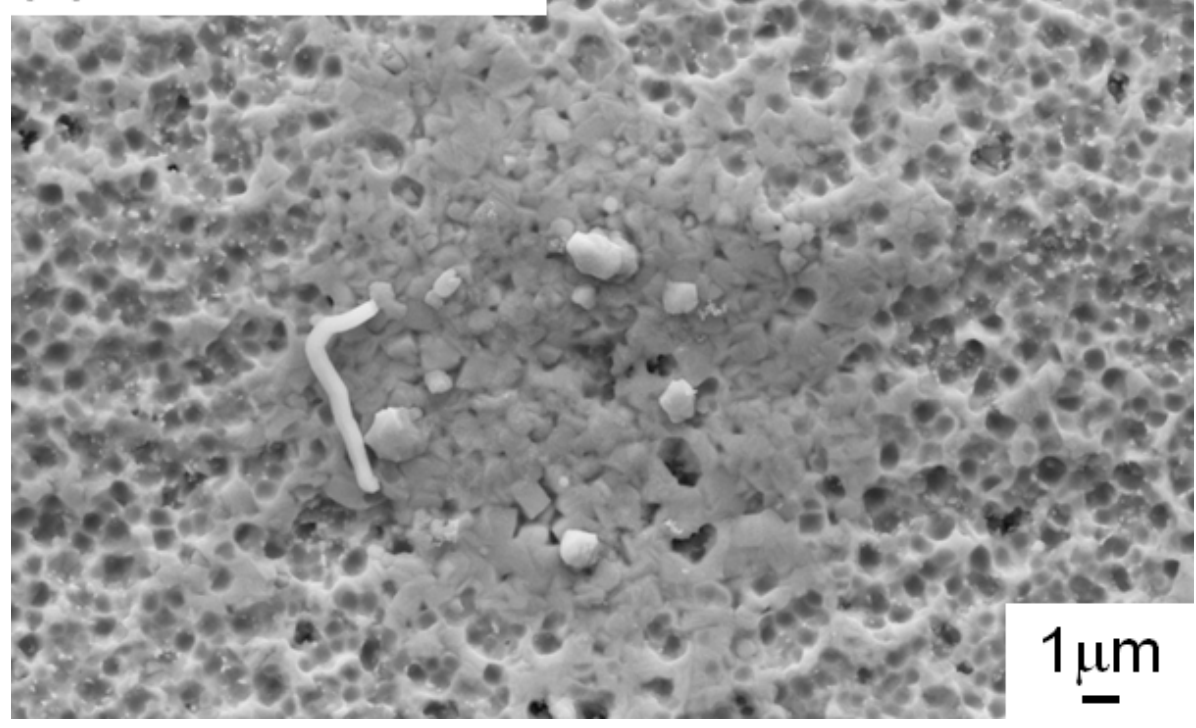

Figure 21 
(a) Native air formed oxide

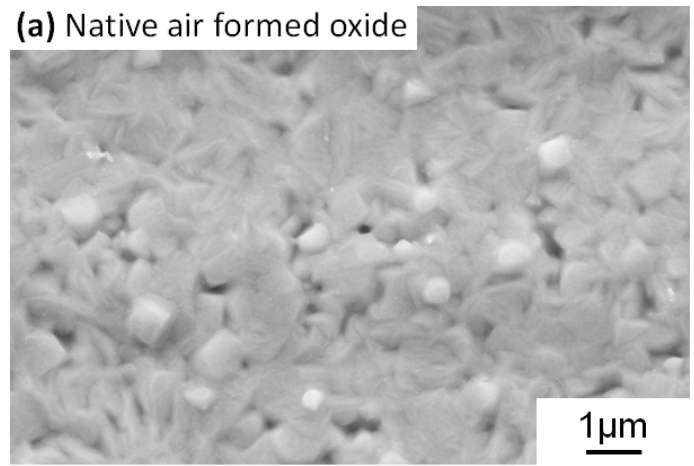

(c) $20 \mathrm{~min}$

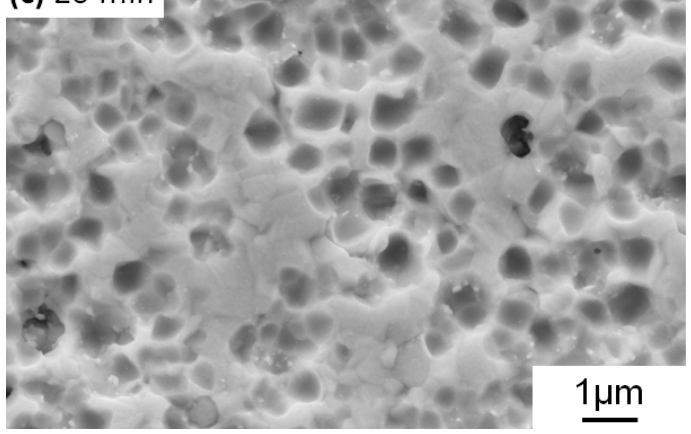

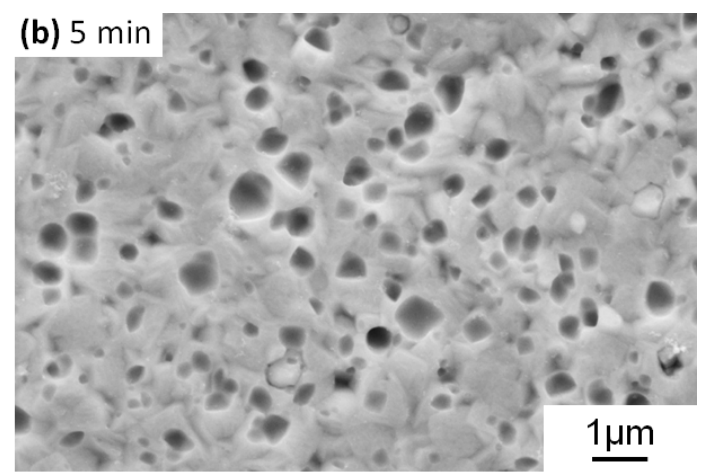

(d) $30 \mathrm{~min}$

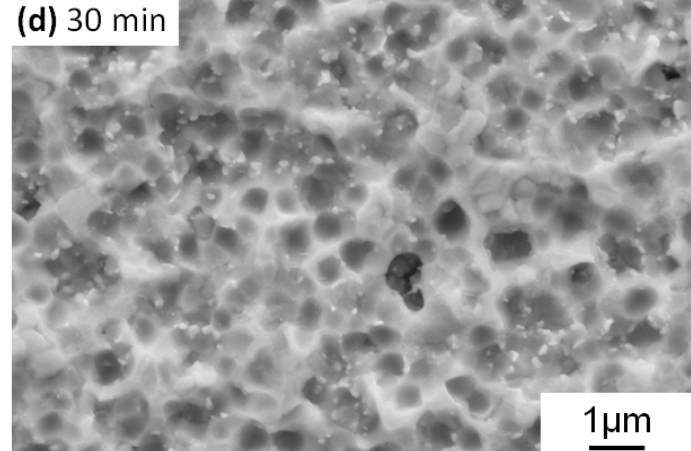

Figure 22 